\title{
Study on Bending Performance of Epoxy Adhesive Prefabricated UHPC-Steel Composite Bridge Deck
}

\author{
Jinlong Jiang $\mathbb{D}^{1}{ }^{1}$ Yang Zou $\mathbb{D},{ }^{1}$ Jun Yang, ${ }^{1}$ Jianting Zhou, ${ }^{1}$ Zhongya Zhang, \\ and Zulin Huang ${ }^{2}$ \\ ${ }^{1}$ State Key Laboratory of Mountain Bridge and Tunnel Engineering, Chongqing Jiaotong University, Chongqing 400074, China \\ ${ }^{2}$ Key Laboratory of New Technology for Construction of Cities in Mountain Area, School of Civil Engineering, \\ Chongqing University, Chongqing 400030, China
}

Correspondence should be addressed to Yang Zou; zouyang@cqjtu.edu.cn

Received 31 December 2020; Revised 7 February 2021; Accepted 4 March 2021; Published 15 March 2021

Academic Editor: Qian Zhang

Copyright (C) 2021 Jinlong Jiang et al. This is an open access article distributed under the Creative Commons Attribution License, which permits unrestricted use, distribution, and reproduction in any medium, provided the original work is properly cited.

UHPC has high strength, high toughness, and excellent durability. For orthotropic steel bridge deck pavement, UHPC can significantly increase the bridge deck's stiffness and then solve the problems of fatigue cracking and pavement damage of the bridge deck. However, if UHPC adopts cast-in-place construction, its self-shrinkage can easily cause shrinkage cracks, and it requires high maintenance conditions. Meanwhile, the traditional stud connection will bring a great deal of welding work and cause welding fatigue. In contrast, prefabricated UHPC pavement and orthotropic steel bridge deck can greatly reduce the amount of welding of studs on the bridge deck through epoxy bonding, thus speeding up the construction process and avoiding the risk of cracking caused by UHPC self-shrinkage. In order to consider the influence of the surface state of interface and ratio of shear span to depth on flexural behavior of epoxy adhesive prefabricated UHPC-steel composite bridge deck, positive bending moment loading test with different ratios of shear span to depth was carried out, and the failure mode, load-deflection curve, interface slip, and strain distribution of the specimens were obtained. Finally, based on the cohesive interface element, the prefabricated UHPCsteel epoxy bonding interface was successfully simulated. The test results show that each specimen's loading stage can be divided into the elastic stage, crack initiation stage, interfacial crack propagation stage, interface failure stage, and yield stage. The specimen's ultimate failure is that the interface failure is prior to the yield at the bottom of the steel plate. During the loading process, the bending performance shows that the ultimate load $P_{B_{i}}$ and growth deflection $\Delta \delta_{B_{i} C_{i}}$ of CD-ERA-P- $\lambda_{4.44}$ are higher than those of other specimens in terms of the load-deflection curve. The ultimate load of CD-ERA-P- $\lambda_{3.33}$ is lower than that of CDERG-P- $\lambda_{3.33}$, which decreases by $4.6 \%$, but the increasing deflection increases by $75 \%$. Simultaneously, the interface slip of the specimen is similar, which further shows that the specimen has the best bending performance when the surface of the steel plate is rough $(R)$ and the surface of the prefabricated UHPC plate is grooved $(A)$. No matter what kind of surface is used at the interface, the reduction of the ratio of shear span to depth will aggravate the ultimate failure of the interface and the cracking of the precast UHPC slab. Finally, the bending performance of epoxy adhesive prefabricated UHPC-steel composite bridge deck is successfully simulated based on the cohesive interface element, which is verified by the test results.

\section{Introduction}

Due to its advantages of light deadweight and high strength, the orthotropic steel bridge deck is the long-span steel bridge's main deck form. However, a wide range of application practice shows that there is fatigue cracking and pavement layer damage of the orthotropic steel bridge deck ([1], [2]). These defects can be mainly attributed to insufficient local stiffness of bridge deck, weld density, and design and manufacturing defects ([3-5]).

The adoption of rigid concrete pavement installation of orthotropic steel bridge decks can improve the deck stiffness and thus reduce the cracking risk of orthotropic steel bridge decks $([6-8])$. Compared with the orthotropic bridge deck of asphalt pavement, the orthotropic steel bridge deck of concrete pavement has a better anti-fatigue performance. 
However, there are still problems with concrete pavement cracking and steel reinforcement corrosion [9]. Therefore, from the perspective of improving the crack resistance and durability of conventional concrete, engineering cement composite material (ECC) and ultra-high performance concrete (UHPC) are concrete materials with better performance $([10,11])$. While achieving durability [10], temperature resistance [12], and impact resistance [13] improvement, ECC can guarantee high ductility under high strength (Tensile strain greater than 3\% [14]) and has been applied in engineering structures $([15,16])$. As a kind of ultra-strong toughened concrete, UHPC is usually composed of cement, fine aggregate, high-strength micro steel fiber, admixture, water, and other raw materials [17]. Compared with conventional concrete, UHPC has high mechanical strength [18], high toughness [19], and better durability [20], which can avoid the cracking of concrete in the composite bridge deck, significantly increase the stiffness of composite bridge deck, and has been widely used in improving structural performance ([21-26]).

However, cast-in-place UHPC on orthotropic steel deck will bring in some problems. First of all, the spontaneous shrinkage rate of UHPC at $36 \mathrm{~h}$ after cast-in-situ can reach more than $440 \mu \varepsilon$ [27], and the structure is prone to crack development caused by shrinkage under constrained conditions. Secondly, the mechanical performance of UHPC also depends to a large extent on the maintenance environment after on-site pouring. Based on these problems, the applicability of cast-in-place UHPC is limited to a certain extent, while the prefabricated UHPC plate can well avoid the above problems [28]. This is because the UHPC plate is prefabricated and maintained in a good environment in the factory, and the self-shrinkage is not constrained by the external boundary.

In the steel-concrete composite bridge deck, UHPC, as the rigid pavement layer, can alleviate the fatigue and cracking of the bridge deck structure and enhance the anticracking performance of the pavement layer ([29, 30]). However, the combined action between concrete and steel largely depends on the interface's reliability [31]. Under the influence of the steel-concrete connection mode, at present, the UHPC and the orthotropic bridge panel can be divided into the following two types of connection modes: one is mechanical connection parts, such as studs [32]; the other is adhesives, such as epoxy resins [33]. The stud connection technology has been relatively mature, which can ensure the strong connection between the steel bridge deck and the prefabricated UHPC plate. However, in practical engineering, a steel bridge deck often needs to be welded with many studs, which will inevitably introduce welding defects and residual stresses while increasing time and cost, thus reducing the anti-fatigue performance of orthotropic bridge deck [34]. Secondly, when connecting the prefabricated UHPC plate and the orthostatic steel bridge deck, many castin-place holes need to be reserved on the prefabricated UHPC plate, which increases the manufacturing difficulty of the prefabricated UHPC plate. In contrast, the epoxy adhesive method can solve the problem caused by many welded studs. When epoxy bonding is used at the steel- concrete interface, the surfaces of the both steel and concrete are fully bonded, avoiding uneven shear transfer [35] and stress concentration caused by welding studs ([36, 37]). Meanwhile, the epoxy bonding method is simple and convenient for the prefabrication of UHPC plate [38]. Predictably, the epoxy bonding method at the interface can significantly reduce the welding of the bolts on the bridge deck, accelerate the construction progress, and reduce the complexity of the construction process.

Duan et al. [33] carried out a positive bending moment loading test on the UHPFRC-steel composite bridge deck with the epoxy-glued interface. They found that when the mid-span section reached 0.3 times the ultimate strain, the composite bridge deck's flexural rigidity was 12.7 times higher than that of the steel plate. He et al. [35] conducted the shear test of the UHPC-steel interface and the positive bending moment loading test of the prefabricated UHPC-steel composite bridge deck. They designed six interface shear specimens and one fullsize bridge deck specimen, respectively. The test results show that when epoxy bonding is used at the UHPC-steel interface, the steel plate's surface treatment is poor, and the shear strength is $1.8-2.1 \mathrm{MPa}$. The orthotropic composite bridge deck with epoxy adhesive has better ductility and higher bearing capacity and can guarantee the connection between UHPC pavement and steel bridge deck. Buitelaar [39] studied the orthotropic steel bridge deck's concrete pavement scheme and found that the stress concentration near the interface could be avoided when the steel plate surface was polished and applied with epoxy adhesive before UHPC was poured. When the composite bridge panel is bent, the interface's normal bonding strength is $3 \sim 5 \mathrm{MPa}$, and the tangential shear strength of the interface is $11-13 \mathrm{MPa}$. Wang et al. [40] compared the UHPC-steel composite beam's bending performance with epoxy bonding interface and the stud connection interface. They found that the composite beam's ultimate bearing capacity differs by $6.8 \%$ under two different interface states. The test result shows that the epoxy bonding method can meet the standard stud interface connection requirements in UHPC-steel composite beams. The above research results show that epoxy bonding between the UHPC pavement layer and the orthogonal anisotropic bridge deck is effective. However, the surface state of the interface and the ratio of shear span to depth will significantly affect the interface bond strength, thereby affecting the composite bridge deck's bending performance. Therefore, considering the above two factors, this paper studies the bending performance of epoxy adhesive prefabricated UHPC-steel composite bridge deck.

In order to explore the bending performance of epoxy adhesive prefabricated UHPC-steel composite bridge deck, this paper considered the influence of surface treatment of steel plate and prefabricated UHPC plate and determined the failure mode, load-deflection curve, interface slip, and strain distribution of the specimen through positive bending moment loading tests with different ratio of shear span to depth. Finally, the finite element simulation method of 
prefabricated UHPC-steel composite bridge panel considering the influence of interface performance was established, and the finite element model was verified according to the test results.

\section{Test Procedure}

2.1. Specimen Design. For specimen design information, see Table 1 and Figure 1. The component sizes of all specimens were as follows: the size of the steel plate was $500 \mathrm{~mm} \times 150 \mathrm{~mm} \times 8 \mathrm{~mm}$, the size of the prefabricated UHPC plate was $500 \mathrm{~mm} \times 150 \mathrm{~mm} \times 35 \mathrm{~mm}$, and the thickness of the epoxy layer was $2 \mathrm{~mm}$. In particular, steel plates and prefabricated UHPC plates were bonded by epoxy. The surface of the steel plate and the prefabricated UHPC plate at the interface need to be treated. The specific treatment methods can be divided into the following three types of surfaces: (1) Rough surface(R) of steel plate. The surface of the steel plate needed to be polished rough according to the specification. (2) Groove surface (G) of prefabricated UHPC plate. There were nine grooves on the prefabricated UHPC plate's surface, with the dimension of $150 \mathrm{~mm} \times 10 \mathrm{~mm} \times 3 \mathrm{~mm}$, and the longitudinal spacing along the plate was $50 \mathrm{~mm}$. (3) Aggregate surface(A) of prefabricated UHPC plate. The prefabricated UHPC plate's surface needed to be polished until the aggregate was exposed. In addition, the ratio of shear span to depth $(\lambda)$ of the specimen was designed to be 4.44 and 3.33, respectively. Therefore, according to the surface treatment and ratio of shear span to depth, the specimens can be named as six specimens in Table 1.

Note: CD stands for composite deck. $E$ means the interface is bonded by epoxy. $R, \mathrm{G}$, and A, respectively, indicate the Rough surface of the steel plate, Groove surface of the prefabricated UHPC plate, and Aggregate surface of the prefabricated UHPC plate. P represents positive bending moment loading. $\lambda_{4.44}$ and $\lambda_{3.33}$ indicate that the ratio of shear span to depth is 4.44 and 3.33, respectively.

2.2. Specimen Preparation. To ensure adequate adhesion between the prefabricated UHPC plate and the steel plate, the use of epoxy adhesive shall be in accordance with the manufacturer's instructions. The whole manufacturing process of the specimen is shown in Figure 2. First of all, UHPC was naturally maintained for 3 days after cast-inplace in the prepared template. After the UHPC strength reached the standard, the template was removed, and steam curing was carried out for 3 days at $95^{\circ} \mathrm{C}$. Secondly, the steel plate and prefabricated UHPC plate need to be surface treated according to the design requirements. The rough surface $(R)$ of the steel plate, groove surface $(G)$ of precast UHPC plate, and aggregate surface (A) of precast UHPC plate are shown in Figure 2(c). After cleaning the surface of the prefabricated UHPC plate and steel plate, the quantitative epoxy adhesive shall be applied from the center of the surface of the prefabricated UHPC plate and steel plate to the surrounding areas. The thickness of the epoxy layer of the prefabricated UHPC plate was $1.5 \mathrm{~mm}$, and that of the steel plate was $0.5 \mathrm{~mm}$. After that, to avoid the loss of bonding ability due to the premature hardening of epoxy adhesive, the steel plate should be placed on the surface of the prefabricated UHPC plate in time, and the appropriate force should be applied to make them fit closely. Finally, to ensure the epoxy bonding strength, the specimens need to be naturally cured for 7 days. After curing for strength, the surface was brushed with white paint.

2.3. Material Properties. Table 2 lists the UHPC mix proportion used in this test. The volume content of steel fiber in UHPC is $2 \%$ to ensure the mechanical properties of UHPC. The steel fiber's diameter and length are $0.12 \mathrm{~mm}$ and $8 \mathrm{~mm}$, respectively, and the yield strength is more than $1200 \mathrm{MPa}$. The amount of other raw materials is shown in the table. In particular, the data in Table 2 are from the research of Zou et al. [41].

The epoxy resin used in this test is a high-temperature structural adhesive (CBSR-A/B) produced by Carbon Technology Group Co., Ltd., which mainly consists of primary agent CBSR-A and curing agent CBSR-B, with the material weight ratio of $3: 1$. The mechanical properties of the epoxy resin are shown in Table 3.

The mechanical properties of steel and UHPC in epoxy adhesive prefabricated UHPC-steel composite bridge deck are shown in Table 4.

2.4. Test Scheme. The three-point loading scheme was adopted, and the loading instrument was an electronic universal testing machine (MTS Exceed E45.205). According to different ratio of shear span to depth $(\lambda)$ of the specimen, the positive bending moment loading test can be divided into the following two types: (a) Ratio of shear span to depth $\left(\lambda_{1}=4.44\right)$ and (b) Ratio of shear span to depth $\left(\lambda_{2}=3.33\right)$. The loading point and support arrangement of various specimens are shown in Figure 3.

In the figure, $L_{s i}$ is the distance between the center of the support and the end of the composite plate specimen ( $L_{s 1}=50 \mathrm{~mm}, L_{s 2}=100 \mathrm{~mm}$ ); $L_{m i}$ is the distance between the centers of the two supports $\left(L_{m 1}=400 \mathrm{~mm}, L_{m 2}=300 \mathrm{~mm}\right)$; and $H$ is the height of the specimen $(H=45 \mathrm{~mm})$. The loading scheme adopted displacement control loading, and the loading speed was $0.01 \mathrm{~mm} / \mathrm{s}$.

Figure 4 shows the displacement measurement of each measuring point. In the two kinds of positive bending moment loading tests, dial indicator D-1 and dial indicator D-3 were arranged on the top surface of the prefabricated UHPC plate at the center of the support, and dial indicator D-2 was arranged on the bottom surface of the steel plate at the middle of the span. Meanwhile, the dial indicator D-4 and dial indicator D-5 were arranged at the center of the UHPC plate at the end of the specimen to measure the interface slip between the steel plate and the prefabricated UHPC plate.

The strain gauge arrangement on the steel plate's surface and prefabricated UHPC plate of the specimen is shown in Figure 5. In Figure 5(a), strain gauges S-1 S-10 and S-14 are arranged on the transverse side of the steel plate, while strain 
TABLe 1: Details of specimens.

\begin{tabular}{|c|c|c|c|c|c|}
\hline Specimen & Interface thickness & Surface & Load & Ratio of shear span to depth & Number \\
\hline CD-ER-P- $\lambda_{4.44}$ & 2 & $\mathrm{R}$ & $\mathrm{P}$ & 4.44 & 1 \\
\hline CD-ERG-P- $\lambda_{4.44}$ & 2 & $R+G$ & $\mathrm{P}$ & 4.44 & 1 \\
\hline CD-ERA-P- $\lambda_{4.44}$ & 2 & $R+A$ & $\mathrm{P}$ & 4.44 & 1 \\
\hline CD-ER-P- $\lambda_{3.33}$ & 2 & $\mathrm{R}$ & $\mathrm{P}$ & 3.33 & 1 \\
\hline CD-ERG-P- $\lambda_{3.33}$ & 2 & $R+G$ & $\mathrm{P}$ & 3.33 & 1 \\
\hline CD-ERA-P- $\lambda_{3.33}$ & 2 & $R+A$ & $\mathrm{P}$ & 3.33 & 1 \\
\hline
\end{tabular}

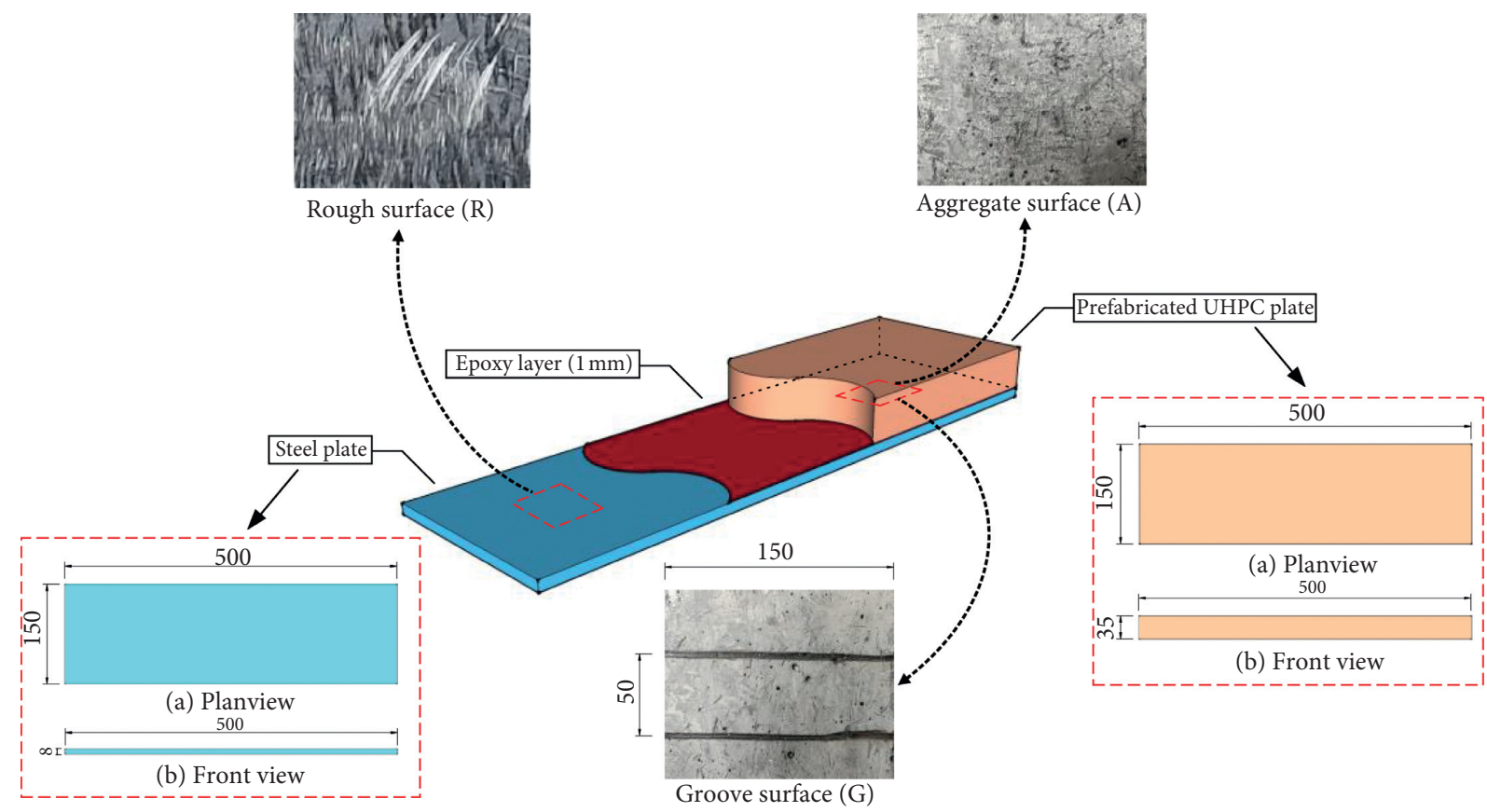

FIGURE 1: Detailed information on the specimen (Unit: $\mathrm{mm}$ ).



(a)

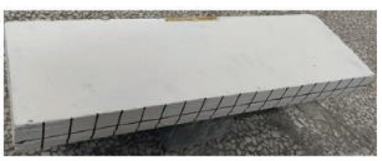

(f)

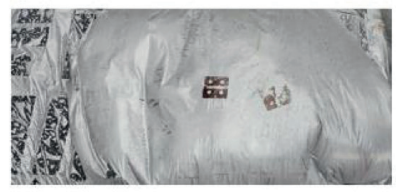

(b)

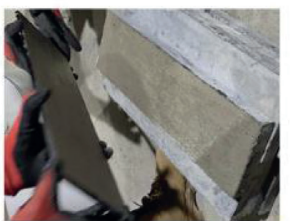

(e)

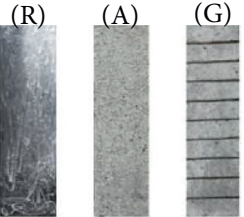

(c)



(d)

Figure 2: The whole manufacturing process of the specimen. (a) Cast in situ UHPC. (b) Steam curing. (c) Surface treatment. (d) Apply epoxy adhesive. (e) Install steel plate. (f) Formed specimen.

gauges S-11 S-13 were set on the transverse side of the prefabricated UHPC plate. The strain gauge S-15 was arranged near the center of the edge line of the prefabricated UHPC plate's top surface, while the strain gauge S-16 was set near the center of the edge line of the bottom surface of the steel plate. The specific arrangement is shown in Figure 5(b). It is worth noting that all strain gauges were only arranged on the surface of one side of the specimen, no matter which type of specimen was in the positive bending moment loading test. 
TABle 2: Mix proportion of UHPC (Table 2 is reproduced from "Study on the Static Performance of Prefabricated UHPC-Steel Epoxy Bonding Interface").

\begin{tabular}{lcc}
\hline Component & Mass ratio & Proportion (\%) \\
\hline Cement & 1.000 & 34.55 \\
Silica fume & 0.250 & 8.64 \\
Quartz sand & 1.100 & 38.01 \\
Quartz flour & 0.300 & 10.37 \\
Water reducing agent & 0.019 & 0.66 \\
Water & 0.225 & 7.77 \\
\hline
\end{tabular}

TABLE 3: Mechanical properties of epoxy resin.

\begin{tabular}{lcccc}
\hline Material & Tensile strength $(\mathrm{MPa})$ & Bending strength $(\mathrm{MPa})$ & Compressive strength $(\mathrm{MPa})$ & Elastic modulus $(\mathrm{MPa})$ \\
\hline CBSR-A/B & 40 & 55 & 70 & 3920 \\
\hline
\end{tabular}

TABLE 4: Mechanical properties of steel plate and prefabricated UHPC plate.

\begin{tabular}{|c|c|c|c|c|c|}
\hline Part & Thickness (mm) & $f_{s}(\mathrm{MPa})$ & $f_{s u}(\mathrm{MPa})$ & $E_{s}(\mathrm{MPa})$ & $v_{s}$ \\
\hline Steel plate & 8 & 225 & 370 & 206000 & 0.3 \\
\hline Prefabricated UHPC plate & 35 & $\begin{array}{c}f_{c}(\mathrm{MPa}) \\
130\end{array}$ & $\begin{array}{c}f_{c t}(\mathrm{MPa}) \\
25\end{array}$ & $\begin{array}{c}E_{c}(\mathrm{MPa}) \\
41000\end{array}$ & $\begin{array}{c}v_{c} \\
0.2\end{array}$ \\
\hline
\end{tabular}

$f_{s}$ is the yield strength of steel plate. $f_{s u}$ is the ultimate strength of steel plate. $E_{s}$ is Young's modulus of steel plate. $v_{s}$ is Poisson's ratio of steel plate. $f_{c}$ is the compressive strength of UHPC. $f_{c t}$ is flexural strength of UHPC. $E_{c}$ is Young's modulus of UHPC. $v_{c}$ is Poisson's ratio of UHPC.

\section{Analysis of Test Results}

3.1. Failure Mode. In the two types of positive bending moment loading tests, the final interface slip and the prefabricated UHPC plate cracks were only concentrated on the same side of the specimen loading centerline. Specimen CDER-P- $\lambda_{4.44}$ and specimen CD-ER-P- $\lambda_{3.33}$ had similar failure characteristics. At the initial stage of loading, the interface between the prefabricated UHPC plate and the steel plate did not begin to slip, and there was no crack on the side of the specimen. When the load of the crack was reached, a weak cracking sound began to appear near the bearing on one side of the specimen, accompanied by the generation of fine cracks at the interface. Later, as the load increased to the specimen's ultimate bearing capacity, the fine cracks at the interface continued to expand. When the load reached the ultimate bearing capacity, the interface's fine longitudinal crack was instantly connected to form a crack, but the interface will not be failed immediately. Instead, the bearing capacity will plummet after the interface slip was to a certain extent. After that, the relative slip at the interface between the prefabricated UHPC plate and the steel plate continued to increase, and cracks near the loading point occurred and continued to grow until the bottom of the steel plate yielded. The final interface slip and crack are shown in Figures 6(a) and $6(\mathrm{~b})$.

Similarly, for specimen CD-ERG-P- $\lambda_{4.44}$ and specimen CD-ERG-P- $\lambda_{3.33}$, they had similar failure characteristics. Compared with specimen CD-ER-P- $\lambda_{4.44}$ and specimen CDER-P- $\lambda_{3.33}$, the difference was that when the load reached the ultimate bearing capacity, the longitudinal fine cracks at the interface were not penetrated, and cracks appeared in the prefabricated UHPC plate near the loading point. After that, the bearing capacity of the specimen decreased instantly and recovered to some extent. At this stage, the fine interface cracks developed but did not penetrate, and there was no visible slip at the interface. When the second ultimate bearing capacity was reached, the specimen's bearing capacity was reduced instantly, the fine interface crack was immediately connected to form a crack, and the crack of the prefabricated UHPC plate near the loading point rapidly expanded. Finally, the failure of the specimen was the yield of the steel plate. The specific interface slip and crack are shown in Figures 6(c) and 6(d).

For the specimens CD-ERG-P- $\lambda_{4.44}$ and CD-ERG-P- $\lambda_{3.33}$, the specimens' phenomenon before loading to the ultimate bearing capacity was consistent with that of the other specimens. When the load reached the ultimate bearing capacity, the interface's fine cracks were connected to form cracks, and cracks began to appear in the prefabricated UHPC plate near the loading point. After that, the specimen's bearing capacity decreased but not rapidly, and a sizeable relative slip occurred near the interface. Cracks in the prefabricated UHPC plate near the loading point were further developed. When the loading continues until the interface crack extends to the middle of the span, the specimen's bearing capacity decreases instantaneously. Finally, before yielding at the bottom of the steel plate, the relative slip at the specimen's interface increased continuously, and the crack near the loading point grew continuously. The final interface slip and crack are shown in Figures 6(e) and 6(f).

3.2. Mid-Span Deflection. Figure 7 describes all specimens' load-deflection curves in the two types of positive bending 


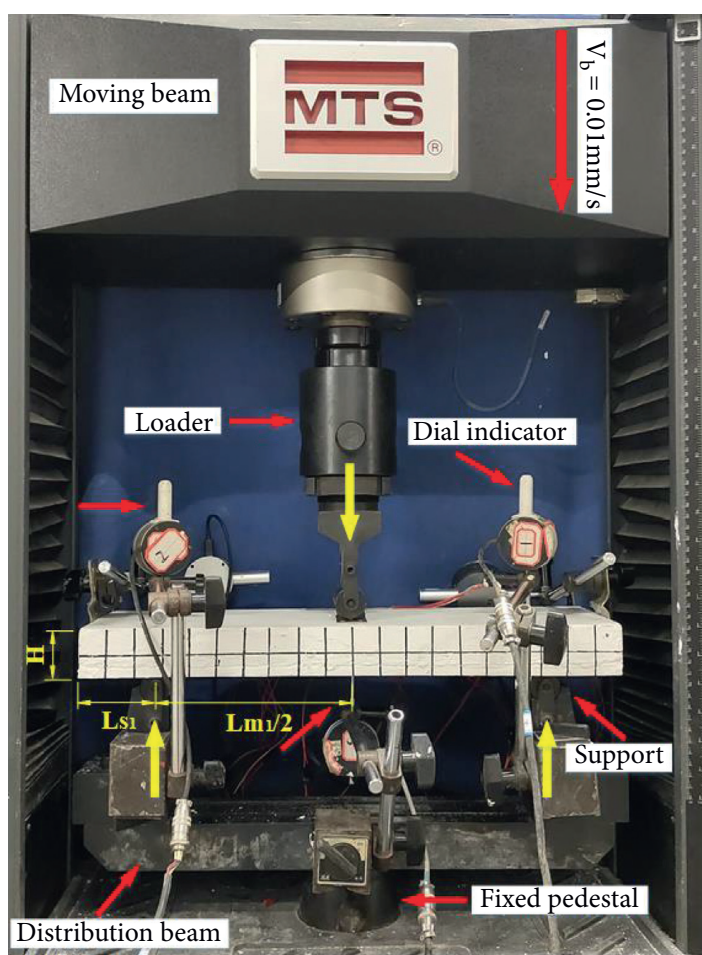

(a)

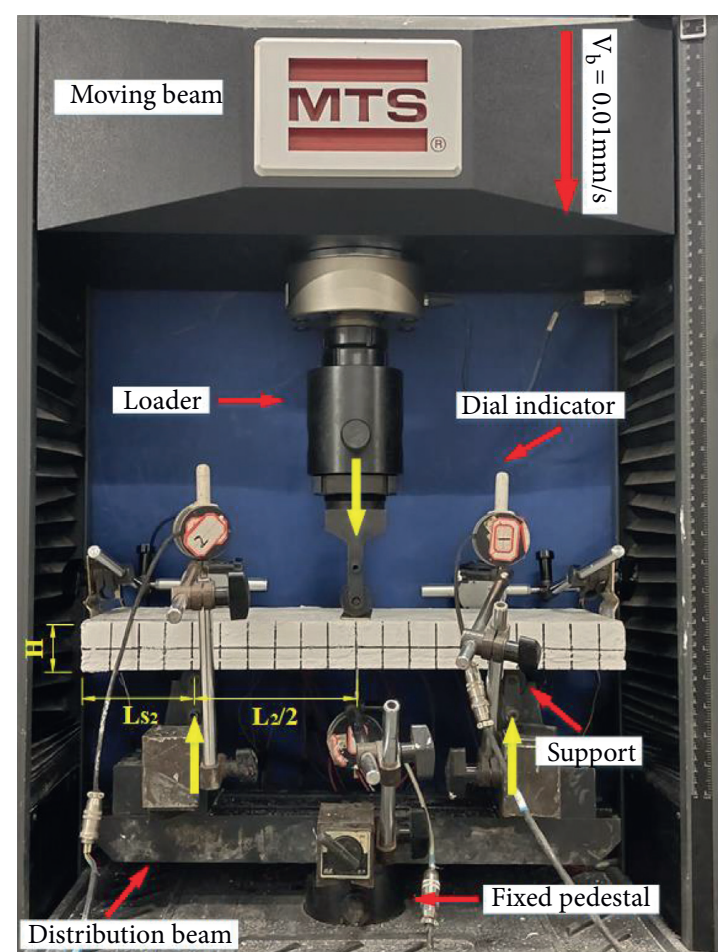

(b)

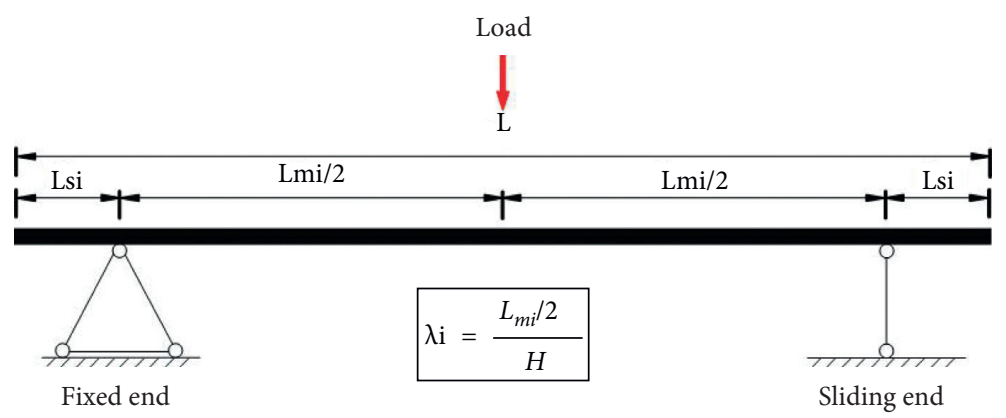

(c)

Figure 3: Loading scheme and design of ratio of shear span. (a) Ratio of shear span to depth $\left(\lambda_{1}=4.44\right)$. (b) Ratio of shear span to depth $\left(\lambda_{2}=3.33\right)$. (c) Design ratio of shear span to depth $\left(\lambda_{1}\right)$.

moment loading tests. According to the failure mode of specimens in Section 3.1, the load-deflection curve can be divided into the following five stages: (1) Elastic stage $\left(\mathrm{O}_{\mathrm{i}} \mathrm{A}_{\mathrm{i}}\right)$; (2) Crack initiation stage $\left(\mathrm{A}_{\mathrm{i}} \mathrm{B}_{\mathrm{i}}\right)$; (3) Interfacial crack propagation stage $\left(\mathrm{B}_{\mathrm{i}} \mathrm{C}_{\mathrm{i}}\right)$; (4) Interface failure stage $\left(\mathrm{C}_{\mathrm{i}} \mathrm{D}_{\mathrm{i}}\right)$; and (5) Yield stage $\left(\mathrm{D}_{\mathrm{i}} \mathrm{E}_{\mathrm{i}}\right)$. As shown in the figure, during the elastic stage, the specimen mainly showed the continuous increase of load without fine cracks at the interface. With the increase of load in the crack initiation stage, fine cracks began to appear at the interface near the bearing and gradually propagate to the middle of the span. In the interfacial crack propagation stage, interface cracks were connected to form an interface slip, and cracks of prefabricated UHPC plate appeared near the loading point. During the interface failure stage, the specimen's bearing capacity decreased instantaneously, and the interface slip and the crack of the prefabricated UHPC plate increased sharply. Finally, in the yield stage, the relative slip at the interface between the prefabricated UHPC plate and the steel plate increased continuously, and the cracks on the side of the precast UHPC plate near the loading point increased continuously until the bottom of the steel plate yields.

Figure 7 lists the ultimate load $P_{B_{i}}$ and the increased deflection $\Delta \delta_{B_{i} C_{i}}$ of the specimen in the interfacial crack propagation stage to evaluate the specimen's bending performance. It can be seen from Figure 7 (a) that when the ratio of shear span to depth was 4.44, the ultimate load $\left(P_{B_{3}}=44.73 \mathrm{kN}\right)$ and the increased deflection $\left(\Delta \delta_{B_{3} C_{3}}=0.46 \mathrm{~mm}\right)$ of the specimen CD-ERA-P- $\lambda_{4.44}$ were higher than those of other specimens. This indicated that compared with other specimens, the specimen CD-ERA-P$\lambda_{4.44}$ had a higher bearing capacity and bending deformation capacity in the interfacial crack propagation stage. However, it should be noted that once entering the interface failure stage, the bearing capacity of specimen CD-ERA-P- $\lambda_{4.44}$ decreased instantaneously. Figure 7 (b) shows that when the 

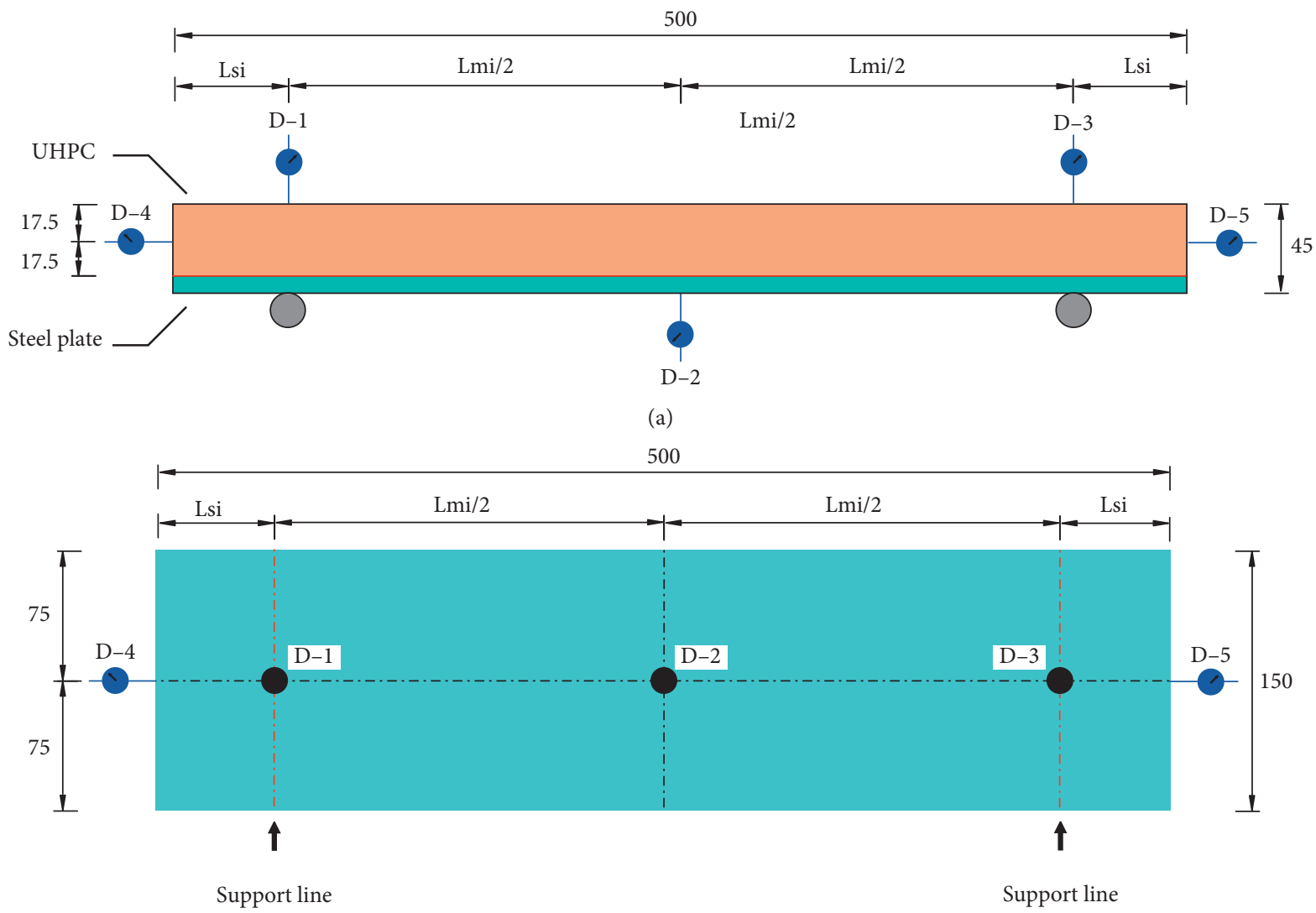

(b)

FIGURE 4: Arrangement of displacement measuring points. (a) front view and (b) plan view of displacement measuring point arrangement for the positive bending moment loading test (unit: $\mathrm{mm}$ ).

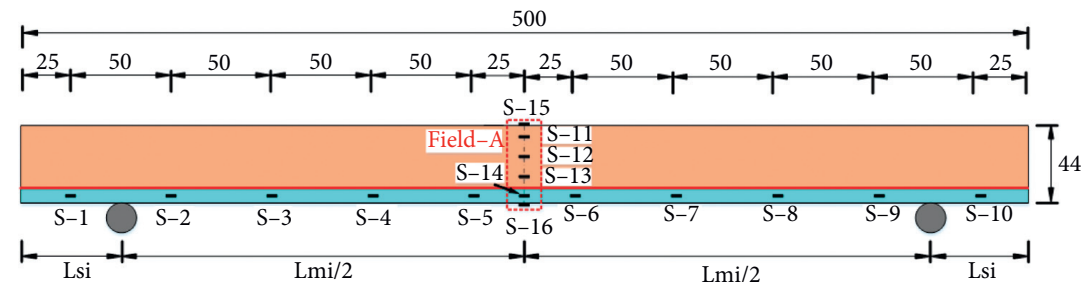

(a)

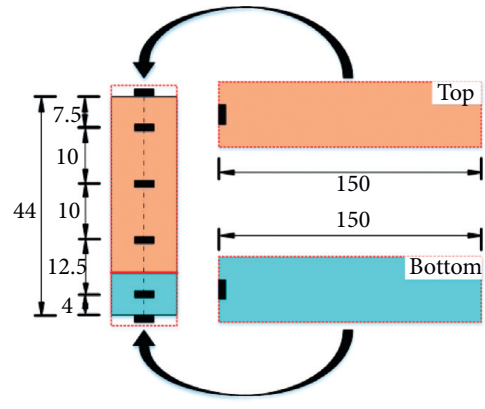

(b)

FIGURE 5: Distribution of Strain gauges. (a) Back view. (b) Field view.

ratio of the shear span to depth was 3.33, the ultimate load $\left(P_{B_{2}}=65.19 \mathrm{kN}\right)$ of CD-ERG-P- $\lambda_{3.33}$ was higher than that of other specimens. However, its bending deformation capacity was the lowest, and the increased value of deflection was $0.20 \mathrm{~mm}$. In contrast, the ultimate load of CD-ERA-P- $\lambda_{3.33}$ was $62.2 \mathrm{kN}$, which was only reduced by $4.6 \%$. In the interfacial crack propagation stage, compared with specimen CD-ERG-P- $\lambda_{3.33}$, the deflection value $\delta_{B_{3}}$ corresponding to the ultimate load of specimen CD-ERA-P- $\lambda_{3.33}$ increased by $107.7 \%$, and the increment of deflection $\Delta \delta_{B_{3} C_{3}}$ in this stage increased by $75 \% \%$, respectively. The results showed that the specimen CD-ERA-P- $\lambda_{3.33}$ had a high bearing capacity and excellent bending and deformation capability during the interfacial crack propagation stage. In summary, when the steel plate surface was a rough surface $(R)$, and the precast UHPC plate surface was an aggregate surface (A), the specimen had excellent bearing capacity and bending deformation ability.

3.3. Interfacial Slip. The load-slip curves of each specimen under the action of the positive bending moment under 


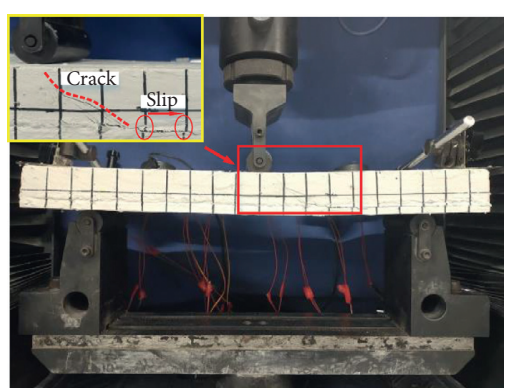

(a)

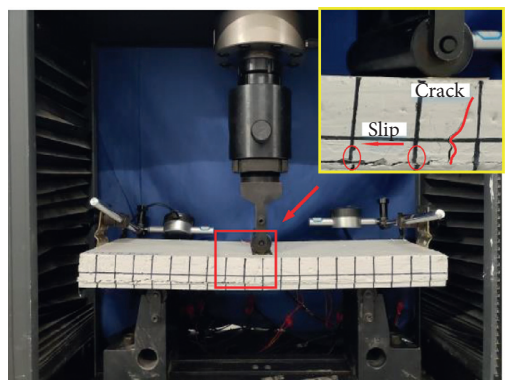

(d)

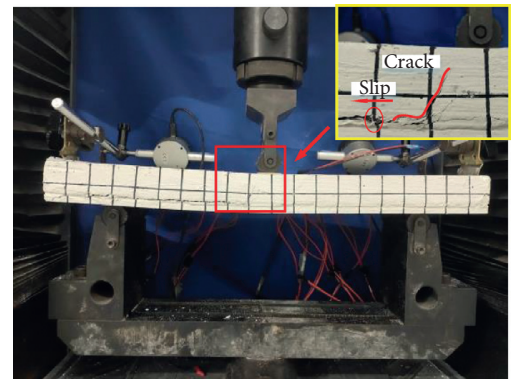

(b)

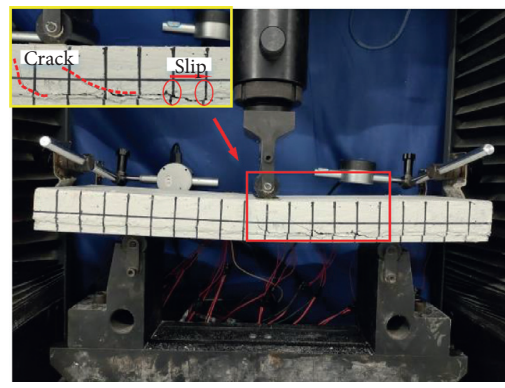

(e)

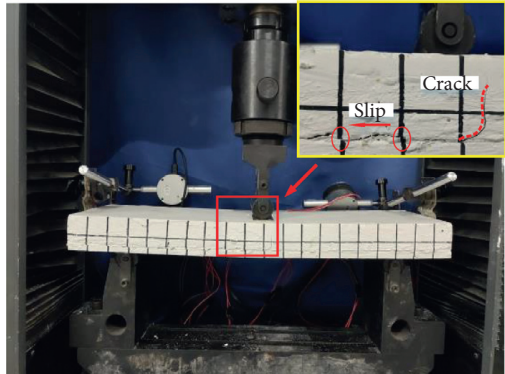

(c)

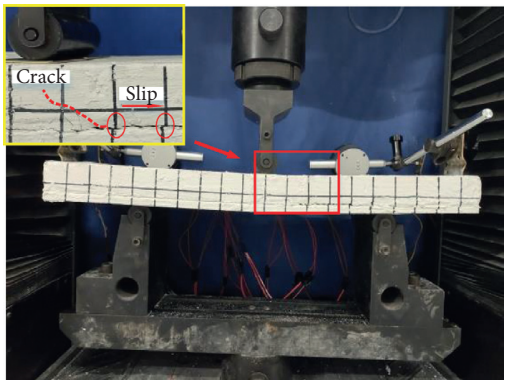

(f)

Figure 6: Failure details. (a) CD-ER-P- $\lambda_{4.44}$ (b) CD-ER-P- $\lambda_{3.33}$. (c) CD-ERG-P- $\lambda_{4.44}$ (d) CD-ERG-P- $\lambda_{3.33}$. (e) CD-ERA-P- $\lambda_{4.44}$ (f) CDERA-P- $\lambda_{3.33}$.

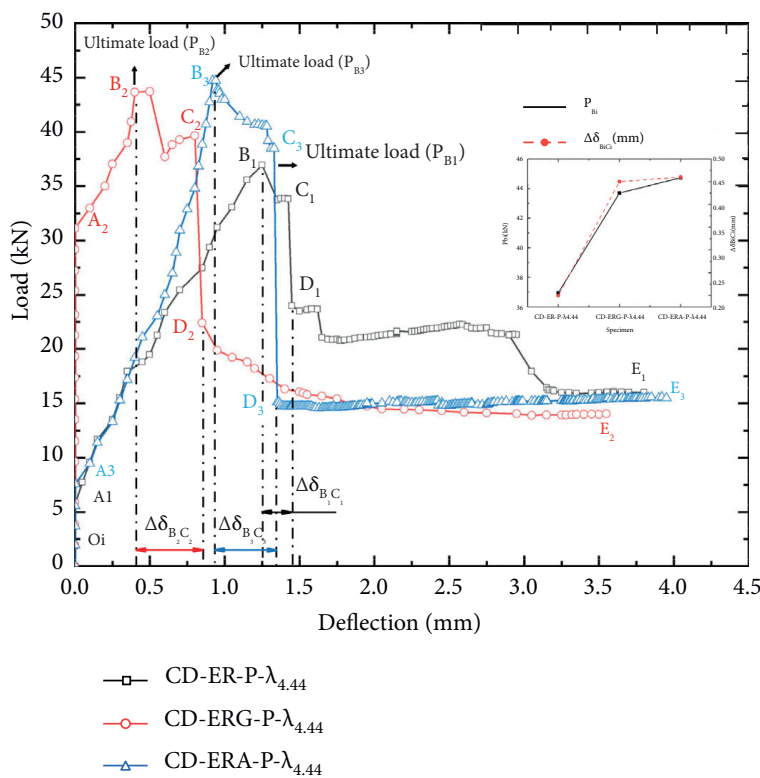

(a)

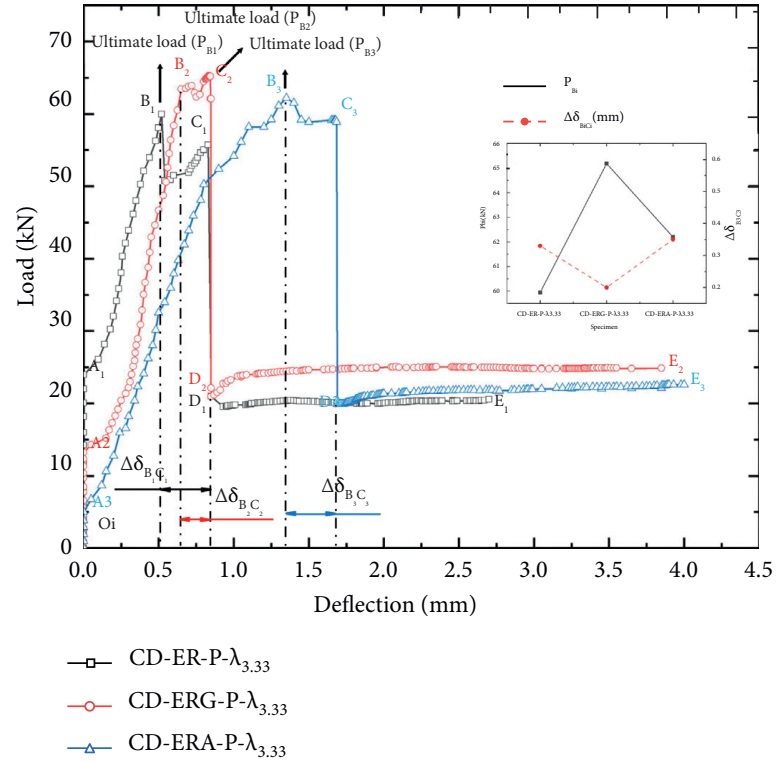

(b)

Figure 7: Load-deflection curves of specimens. (a) Ratio of shear span to depth $(\lambda 1=4.44)$. (b) Ratio of shear span to depth $(\lambda 2=3.33)$.

different ratios of shear span to depths are listed in Figure 8. In the elastic stage $\left(\mathrm{O}_{\mathrm{i}} \mathrm{A}_{\mathrm{i}}\right)$ and crack initiation stage $\left(\mathrm{A}_{\mathrm{i}} \mathrm{B}_{\mathrm{i}}\right)$, no interfacial slip was generated in each specimen. In the interfacial crack propagation stage $\left(\mathrm{B}_{\mathrm{i}} \mathrm{C}_{\mathrm{i}}\right)$, the cracking of the prefabricated UHPC-steel epoxy bonding interface was mainly manifested as a reduction in bond strength, but not a loss, and the maximum slip at the interface was $0.72 \mathrm{~mm}$. At the interface failure stage $\left(\mathrm{C}_{\mathrm{i}} \mathrm{D}_{\mathrm{i}}\right)$, the bonding interface was further cracked until most specimens' bonding interface lost its bonding strength instantly. The slip growth at the interface was all lower than $0.05 \mathrm{~mm}$. After that, the relative slip at the interface increased until the bottom of the plate yields. The ultimate load of each specimen and interface slip during interface failure is shown in Table 5. 


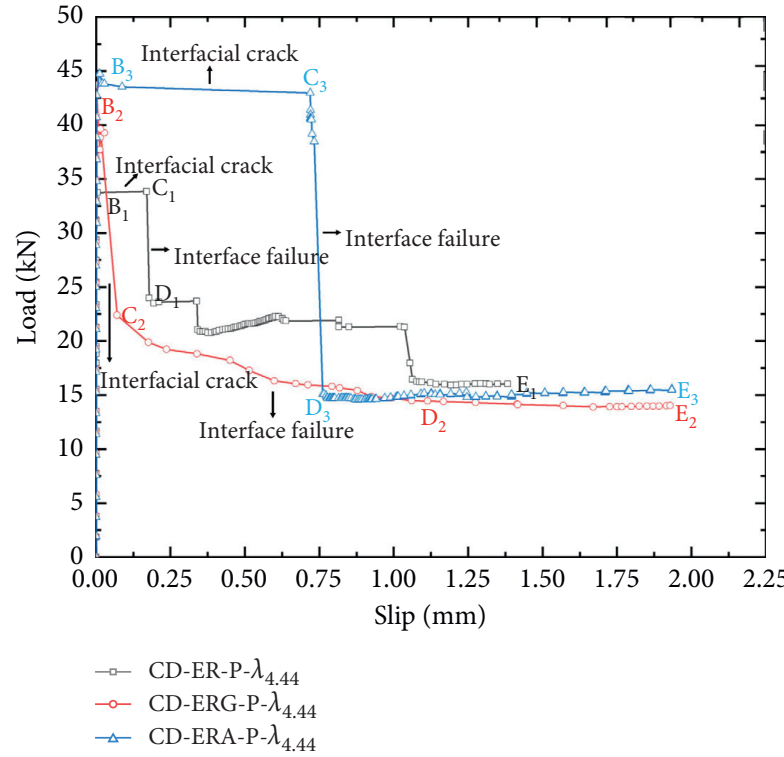

(a)

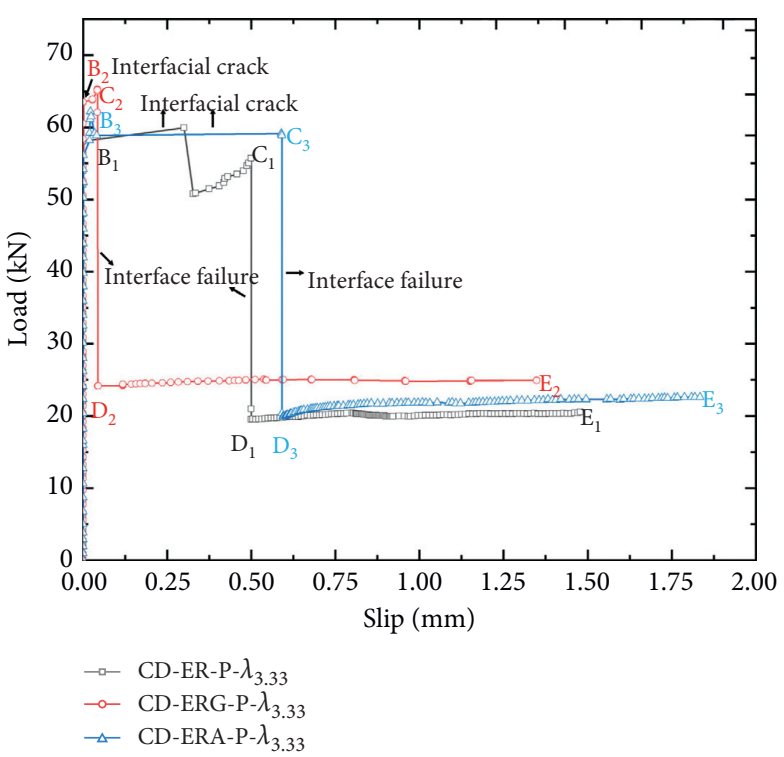

(b)

FIgURE 8: Load-slip curves of specimens. (a) Ratio of shear span to depth $(\lambda 1=4.44)$. (b) Ratio of shear span to depth $(\lambda 2=3.33)$.

TABLE 5: Load-slip curve information of specimens.

\begin{tabular}{lcccc}
\hline Ratio of shear span to depth & Specimen & $P_{B_{i}}(\mathrm{kN})$ & $\eta(\%)$ & $\delta_{b}(\mathrm{~mm})$ \\
\hline \multirow{3}{*}{4.44} & CD-ER-P- $\lambda_{4.44}$ & 36.94 & 0 & 0.179 \\
& CD-ERG-P- $\lambda_{4.44}$ & 43.70 & 18.3 & 0.071 \\
\hline \multirow{2}{*}{3.33} & CD-ERA-P- $\lambda_{4.44}$ & 44.73 & 21.1 & 0.762 \\
& CD-ER-P- $\lambda_{3.33}$ & 59.95 & 0 & 0.501 \\
\hline
\end{tabular}

It can be concluded from Table 5 that when the ratio of shear span to depth was 4.44 , the ultimate load of specimen CD-ERA-P- $\lambda_{4.44}$ is higher than the ultimate load of other specimens. In particular, the interfacial slip during interface failure significantly exceeded that of the rest of the specimens, indicating that the specimen CD-ERA-P- $\lambda_{4.44}$ had the highest bearing capacity and excellent interfacial slip ability. In contrast, CD-ERG-P- $\lambda_{4.44}$ had a higher bearing capacity, but the interfacial slip capacity was the worst. When the ratio of shear span to depth was 3.33, compared with specimen CD-ERG-P- $\lambda_{3.33}$, the ultimate load of specimen CD-ERA-P$\lambda_{3.33}$ is reduced by $4.6 \%$, but the interface slip increases significantly when the interface is damaged. Therefore, under different ratios of shear span to depth, when the steel plate surface was a rough surface $(\mathrm{R})$ and the precast UHPC plate surface was an aggregate surface (A), the specimens had higher bearing capacity and the best interface slip capacity.

Note: $P_{B_{i}}$ refers to the ultimate load of all kinds of specimens in the loading process; $\eta$ is the ultimate load growth rate of specimens relative to specimens CD-ER-P$\lambda_{4.44}$ and specimens CD-ER-P- $\lambda_{3.33}$, respectively, when the ratio of shear span to depth is 4.44 and $3.33 ; \delta_{b}$ is the interface slip at interface failure; $\gamma$ is the interfacial slip growth rate of specimens relative to specimens CD-ER-P$\lambda_{4.44}$ and specimens CD-ER-P- $\lambda_{3.33}$, respectively, when the ratio of shear span to depth is 4.44 and 3.33 .

After the test was finished, the prefabricated UHPC plate and steel plate were separated from the interface, and the interface state of the prefabricated UHPC plate and steel plate after failure was obtained, as shown in Figure 9. In the figure, with the loading center line as the boundary, the left side was the failure interface, and the right side was the intact interface. When the interface failure occurred, the cracks on the prefabricated UHPC plate's surface near the loading centerline had been shown by the red dotted line, and the other red dotted lines were the boundaries of different interface failure forms. For the steel plate with a rough surface (R), the specimen CD-ER-P- $\lambda_{4.44}$ showed an epoxy-steel (E$S)$ interface failure and an epoxy-UHPC (E-U) interface failure, with localized failure of the epoxy layer (Figure 9(a)). The interface failure began with the E-S interface failure at the end. In contrast, the interface failure of the specimen CD-ER-P- $\lambda_{3.33}$ began with the failure of the surface of the prefabricated UHPC plate at the end, followed by the E-U interface failure, as shown in Figure 9(b). 


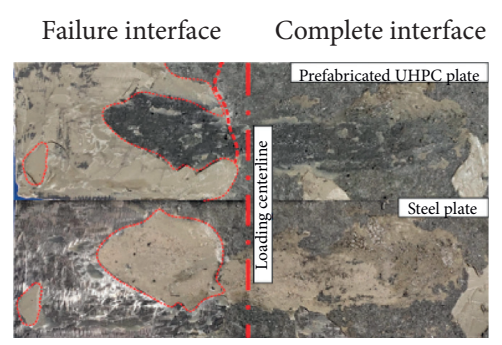

(a)

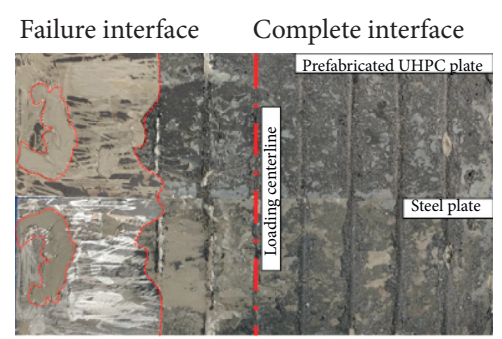

(d)

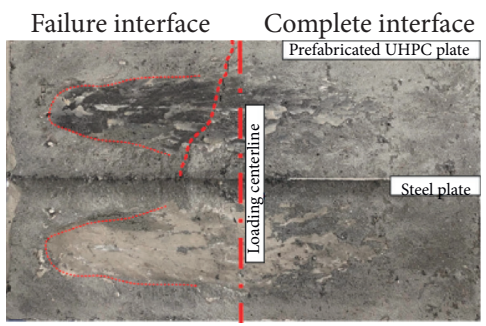

(b)

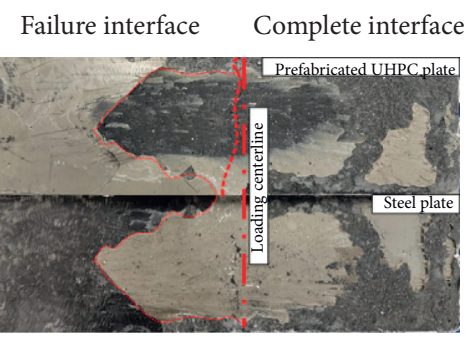

(e)

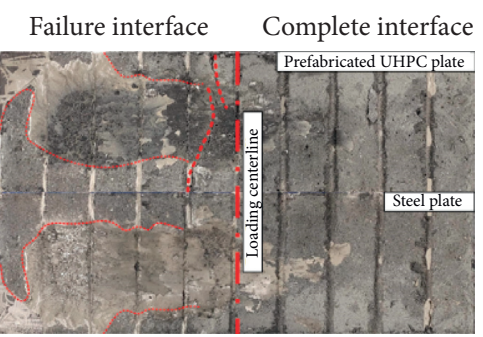

(c)

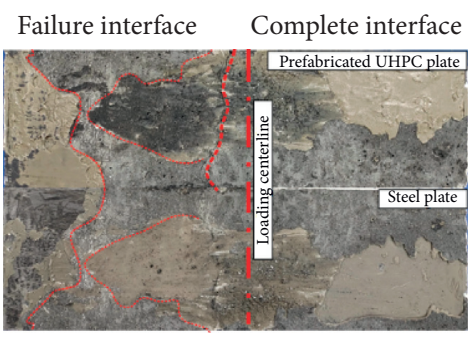

(f)

Figure 9: Failure interfaces of specimens. (a) CD-ER-P- $\lambda_{4.44 \cdot}$ (b) CD-ER-P- $\lambda_{3.33}$. (c) CD-ERG-P- $\lambda_{4.44 .}$ (d) CD-ERG-P- $\lambda_{3.33}$. (e) CD-ERA-P$\lambda_{4.44 .}$ (f) CD-ERA-P- $\lambda_{3.33}$.

Figures $9(\mathrm{c})$ and $9(\mathrm{~d})$ showed that the failure characteristics of the specimen CD-ERG-P- $\lambda_{4.44}$ interface were E-U interface failure and shear failure of epoxy in the groove. E-U interface failure first occurs at the end of the bridge deck. The failure characteristics of the specimen CD-ERG-P- $\lambda_{3.33}$ interface are E-S interface failure, local failure of epoxy layer, E-U interface failure, and shear failure of epoxy in the groove. E-S interface failure first occurs at the end of the bridge deck.

As shown in Figures 9(e) and 9(f), the interface failure of the specimen CD-ERA-P- $\lambda_{4.44}$ began with the E-S interface failure, followed by the E-U interface failure. The first interface failure of the specimen CD-ERA-P- $\lambda_{3.33}$ was the E-S interface, followed by the prefabricated UHPC surface and the E-U interface's failure. Thus, it can be concluded that the reduction of ratio of shear span to depth will lead to more complex and diverse failure modes of the interface between prefabricated UHPC deck and steel plate, and the final interface failure will be more abrupt.

3.4. Strain Distribution. The strain distribution of all specimens along the height at the mid-span section is shown in Figure 10. Figures 10(a) and 10(b) shows the strain distribution of the mid-span section of the specimen with the steel plate's rough surface treatment. It can be seen from the figures that when the load of the specimen was low, the cross section strain had been nonlinear distribution. Moreover, with the increase of the load, the strain distribution became more and more nonlinear. The strain distribution along the section's height indicated that when the steel plate surface of the specimen was a rough surface $(\mathrm{R})$, relative slip always existed at the interface before loading to the ultimate load. Figure $10(\mathrm{c})$ shows that the strain distribution of the specimen CD-ERG-P- $\lambda_{4.44}$ along the mid-span section's height is linear as the load increases to the ultimate load. This strain distribution indicated that there was no slip at the interface of CD-ERG-P- $\lambda_{4.44}$ before loading to the ultimate load, and the interface stiffness of the prefabricated UHPC plate and the steel plate was larger.

In Figures 10(d), 10(e), and 10(f), the strain distribution along the height of the mid-span section of each specimen is linear before loading to the ultimate load. However, when loaded to the ultimate load, the compressive strain in the prefabricated UHPC plate's middle section decreased significantly. The strain distribution showed that before loading to the ultimate load, specimen CD-ERG-P- $\lambda_{3.33}$, specimen CD-ERA-P- $\lambda_{4.44}$, and specimen CD-ERA-P- $\lambda_{3.33}$ had higher stiffness at the interface. But when loaded to the ultimate load, the prefabricated UHPC plate of the specimen had cracked.

\section{Numerical Model}

4.1. Modelling Scheme. In order to fully understand the bending performance of epoxy adhesive prefabricated UHPC-steel composite bridge deck and to study the simulation method of epoxy bonding interface, this paper takes the specimen CD-ERA-P- $\lambda_{4.44}$ and the specimen CD-ERA$\mathrm{P}-\lambda_{3.33}$ as the objects and establishes the interface element for the prefabricated UHPC-steel epoxy bonding interface by using the cohesive model method, which is verified by the load-deflection curve obtained from the test.

In the two types of positive bending moment loading tests, all the steel plates and prefabricated UHPC plates of the specimens are three dimensional 8-node linear solid elements (C3D8). Cushion blocks are set at the fulcrum and loading position of the specimen, the distance between the cushion blocks at the fulcrum and the end of the specimen are $50 \mathrm{~mm}$ and $100 \mathrm{~mm}$, respectively, and the cushion blocks at the loading position are at the mid-span position of the 


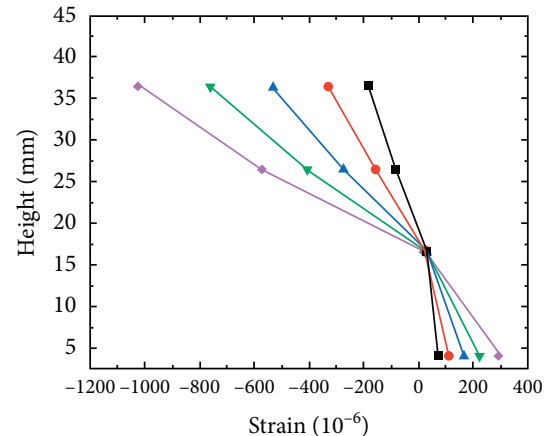

- $\mathrm{P}=7.74 \mathrm{kN} \rightarrow \mathrm{P}=29.36 \mathrm{kN}$

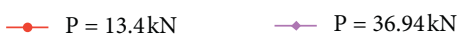

$\leadsto \mathrm{P}=21.25 \mathrm{kN}$

(a)

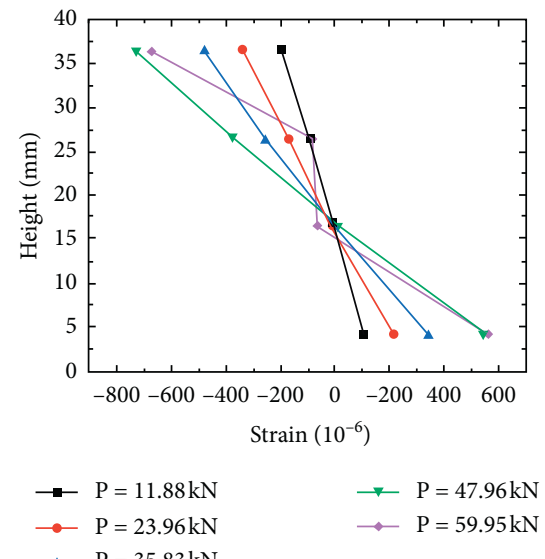

(d)

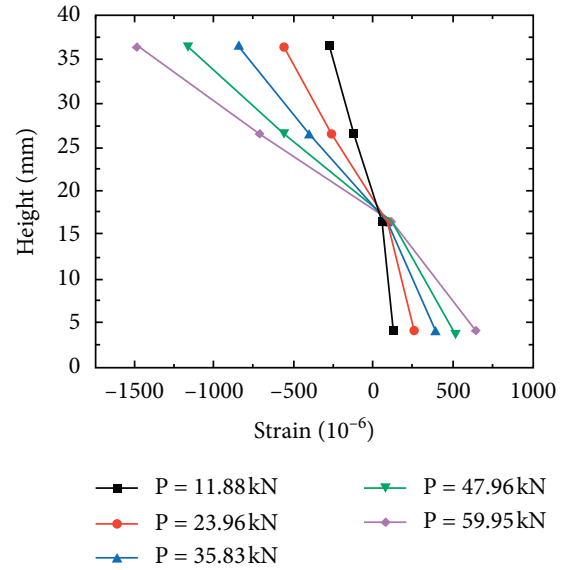

(b)

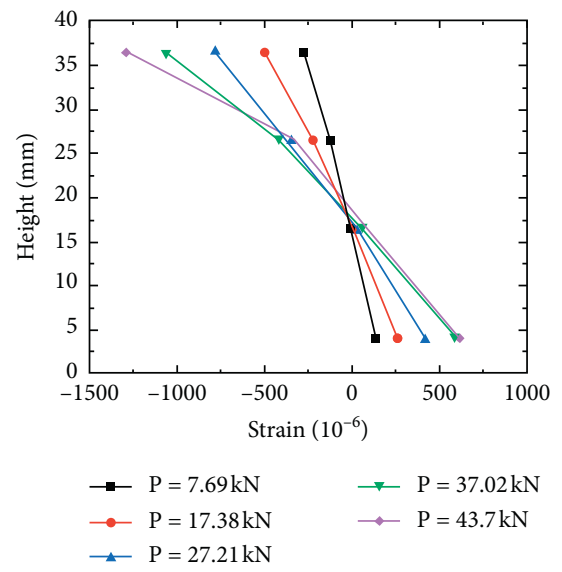

(e)

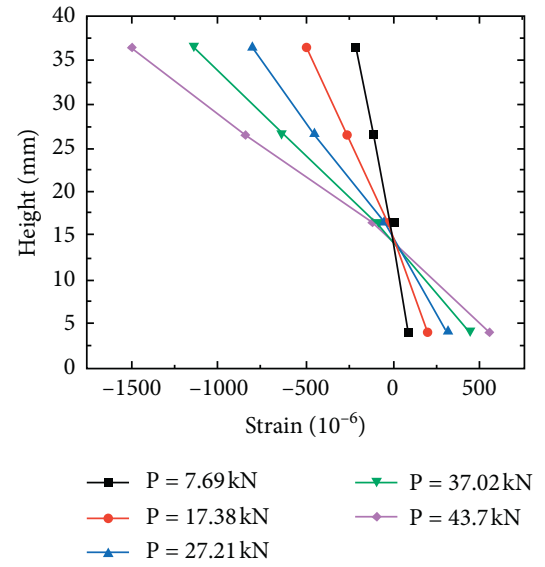

(c)

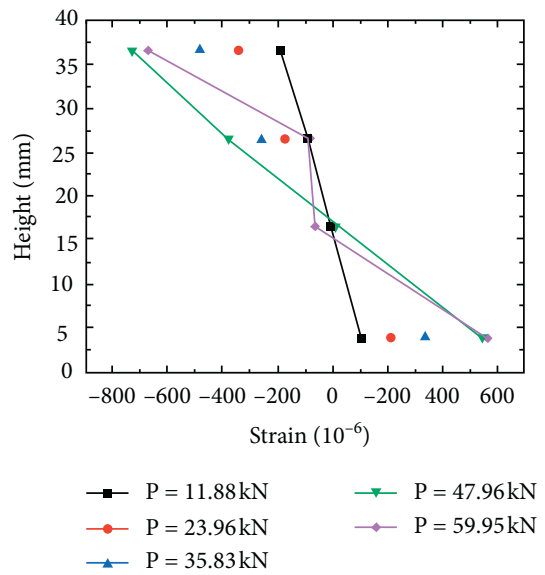

(f)

FIgURE 10: Strain distribution at the mid-span section of specimens. (a) CD-ER-P- $\lambda_{4.44 \cdot}$ (b) CD-ER-P- $\lambda_{3.33}$. (c) CD-ERG-P- $\lambda_{4.44}$. (d) CDERG-P- $\lambda_{3.33}$. (e) CD-ERA-P- $\lambda_{4.44}$. (f) CD-ERA-P- $\lambda_{3.33}$.

specimen, which is constrained by "tie" with the surface of the steel plate and the prefabricated UHPC plate, respectively. Both the fulcrum and the loading point are built on the surface of the cushion block, and the "coupling" constraint is adopted with the surface of the cushion block.

The existing experimental and numerical simulation results show that the cohesive interface element can reasonably simulate the epoxy layer between steel and concrete $[6,40]$. In this method, the zero-thickness cohesive interface element (COH3D8) is established in advance at the interface. The definition of interface cohesion constitutive is realized by the relative displacement between the corresponding nodes on the interface element's upper and lower surfaces. The test results of interfacial properties [42] show that when the epoxy layer of the UHPC-steel interface is thin, the interfacial bonding of the E-S interface is good under pure tension or pure shear. The interface failure is characterized by the tearing of the epoxy layer and surface failure of UHPC. Therefore, in this paper, a zero-thickness cohesive interface unit (COH3D8) is used to simulate the prefabricated UHPC-steel epoxy bonding interface. The modeling and theory of the cohesive interface elements are shown in Figure 11.
4.2. Cohesive Interface Element. As shown in Figure 11, a basic unit of the interface unit between the prefabricated UHPC and the steel plate is selected for analysis. In the unit, nodes 1 to 8 are nodes on the upper and lower surfaces of the cell body, and integral points 1 to 4 are set in the middle of corresponding nodes on the same side. The corresponding displacement values of the node in space are $\left(N_{i}, S_{i}, T_{i}\right), \quad i=1,2, \ldots, 8 . n$ is the normal direction of the interface and the thickness direction of the interface element; $s, t$ represent the two tangent directions perpendicular to the normal direction of the interface.

When subjected to the external load, the interface's upper and lower solid elements are gradually separated, resulting in the corresponding displacement of each node on the interface element. The relative separation displacement of each integral point in the interface method and tangential direction is shown in

$$
\overrightarrow{\delta_{i}}=\left(\delta_{n i}, \delta_{s i}, \delta_{t i}\right)=\left(N_{i}-N_{i+4}, S_{i}-S_{i+4}, T_{i}-T_{i+4}\right), \quad(i=1,2 \ldots 4),
$$

where $\overrightarrow{\delta_{i}}$ is the relatively separated displacement vector of each integral node in the unit; $\delta_{n i}, \delta_{s i}$, and $\delta_{t i}$ are the relative 


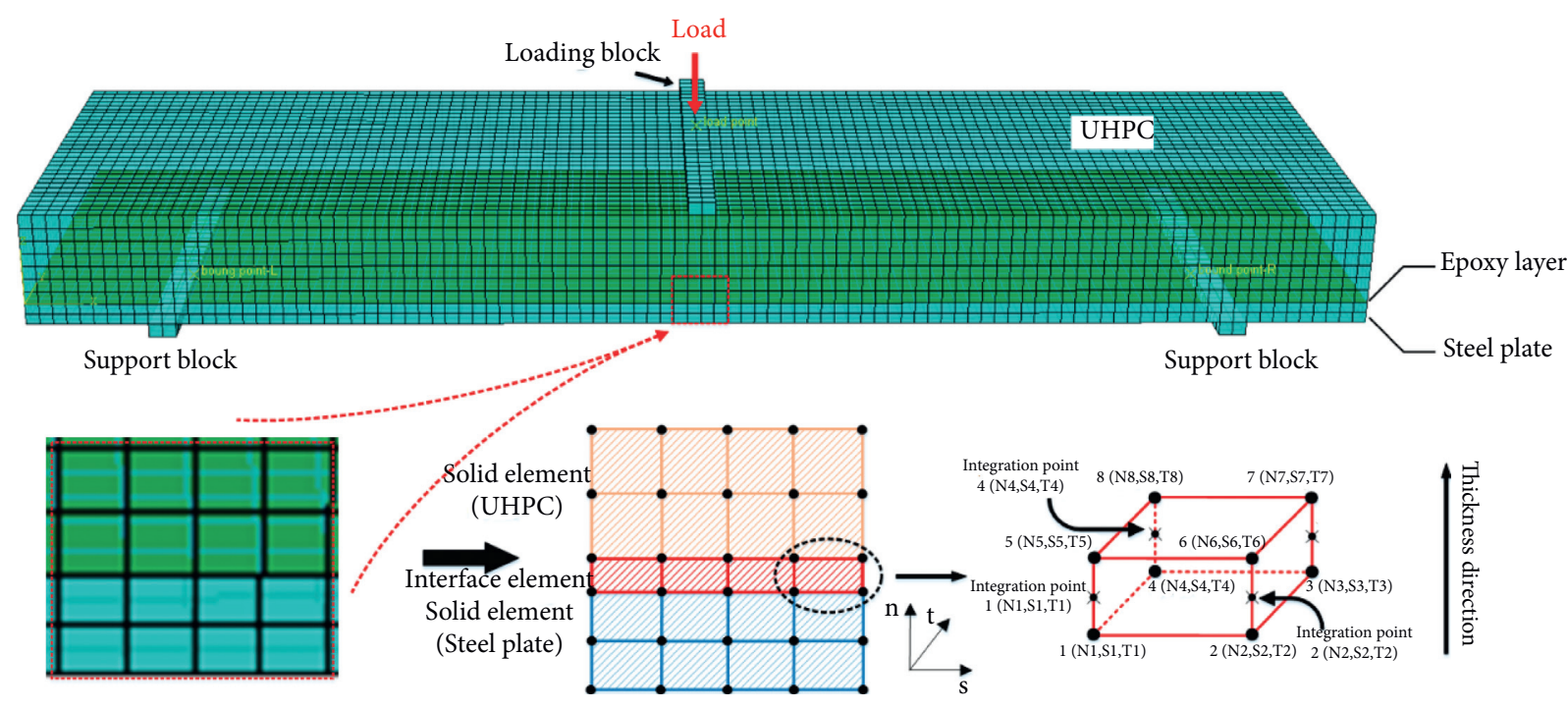

FIGURE 11: Zero-thickness cohesive interface element (COH3D8).
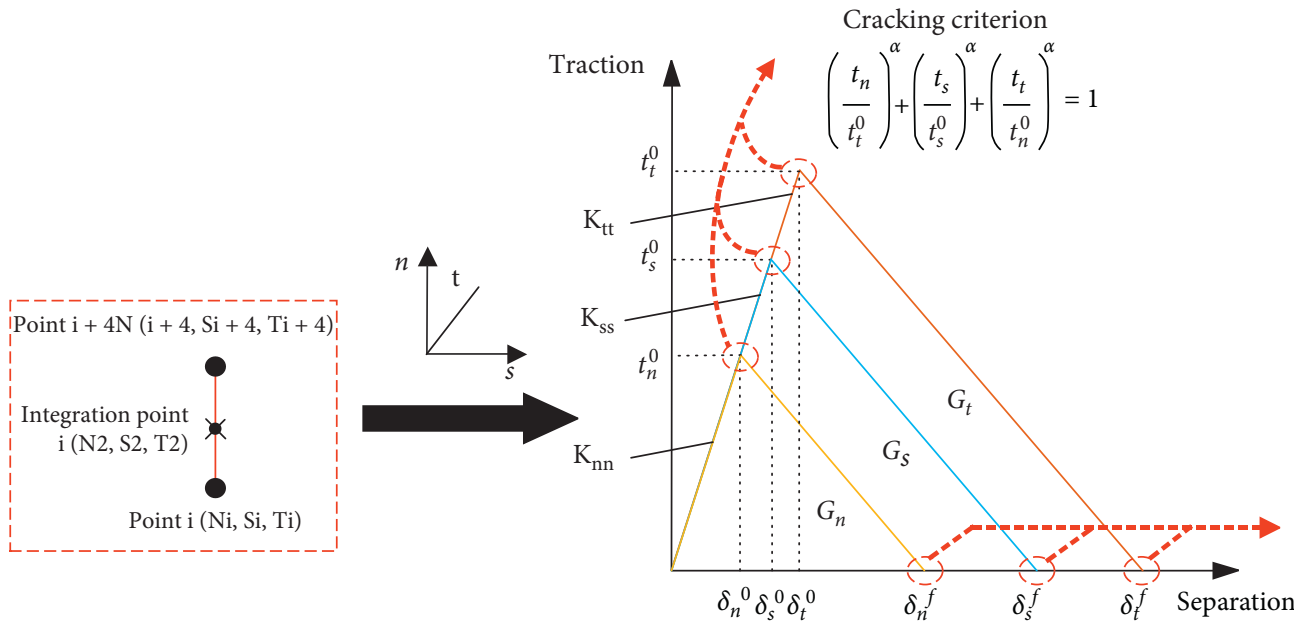

Failure evolution criterion $\left(\frac{G_{n}^{f}}{G_{n}}\right)^{\alpha}+\left(\frac{G_{s}^{f}}{G_{s}}\right)^{\alpha}+\left(\frac{G_{t}^{f}}{G_{t}}\right)^{\alpha}=1$

FIgUre 12: Constitutive model of the cohesive interface element.

separation displacements of the interface in normal and tangential directions at each integral point.

When the upper and lower nodes of the interface begin to separate relatively, the stress of the interface is the function of the displacement of separation. The tractionseparation relationship at each integral point is shown in Equations (2)-(4).

$$
\begin{gathered}
\sigma_{n i}=f\left(\delta_{n i}, \delta_{s i}, \delta_{t i}\right), \\
\tau_{s i}=g\left(\delta_{n i}, \delta_{s i}, \delta_{t i}\right), \\
\tau_{t i}=h\left(\delta_{n i}, \delta_{s i}, \delta_{t i}\right),
\end{gathered}
$$

where $\sigma_{n i}, \tau_{s i}$, and $\tau_{t i}$ are the stresses in the normal and tangent directions of the interface elements at each integral point; $f(*), g(*)$, and $h(*)$ are the functional relations between the normal and tangential stresses and the relative separation displacement.
For the bilinear traction-separation relationship as an example, in the unit, the interfacial and tangential stresses are related to the relative separation displacement in the same direction. The expression of the traction-separation relationship is $\sigma_{n i}=f\left(\delta_{n i}\right) ; \tau_{t i}=h\left(\delta_{t i}\right)$, see Figure 12 for details. In the elastic stage, the interface stress has a linear relationship with the separation displacement. The main parameters are the elastic stiffness $\left(K_{n n}, K_{s s}, K_{t t}\right)$ and the ultimate stress $\left(t_{n}^{0}, t_{s}^{0}, t_{t}^{0}\right)$ in a single direction. In order to consider the interaction of the three directions of the interface, the stress and displacement during the interface cracking are obtained by the cracking criterion. In the failure evolution stage, the interface element's failure process is mainly controlled by the failure evolution criterion. The power law is listed here, and the main parameters are fracture energy $\left(G_{n}, G_{s}, G_{t}\right)$ and material constant $\alpha$. All cohesion model parameters are shown in Table 6. 
TABLE 6: Constitutive parameters.

\begin{tabular}{lccc}
\hline Interface direction & $K_{n n, s s, t t}\left(\mathrm{~N} / \mathrm{mm}^{3}\right)$ & $t_{n, s, t}^{0}(\mathrm{MPa})$ & $G_{n, s, t}(\mathrm{~N} / \mathrm{mm})$ \\
\hline Normal direction & 196 & 1.18 & 0.03 \\
First shear direction & 122 & 5.14 & 0.136 \\
Second shear direction & 122 & 5.14 & 0.136 \\
\hline
\end{tabular}

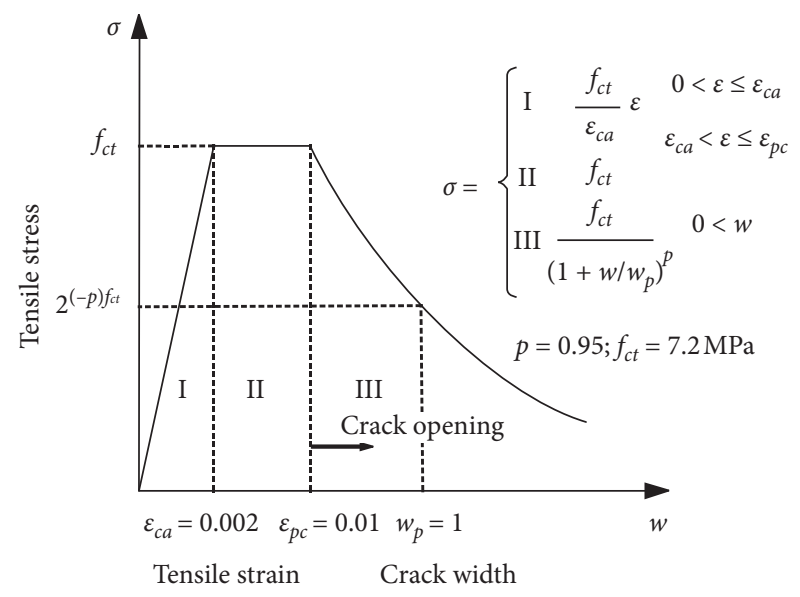

(a)

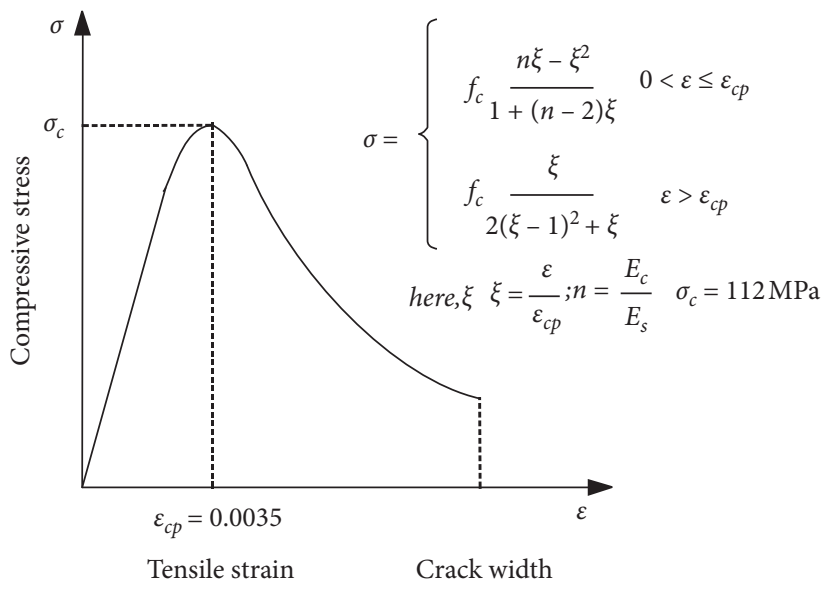

(b)

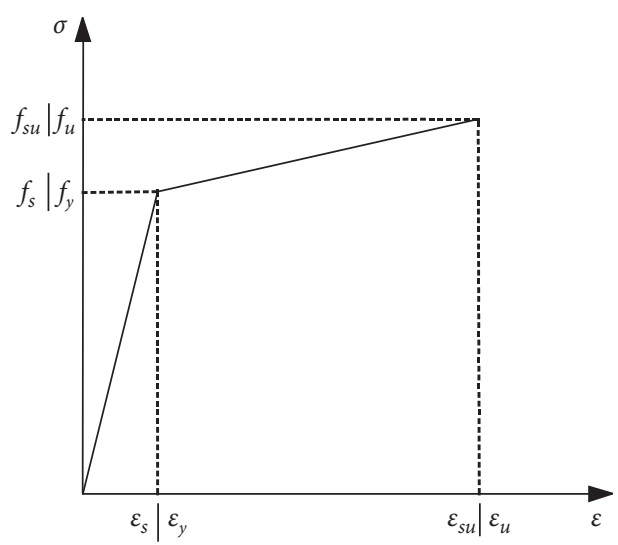

(c)

Figure 13: The tension [43] and compression [44] constitutive of UHPC and the constitutive of steel plate [45]. (a) Tensile constitutive model of UHPC. (b) Compressive constitutive model of UHPC.

(c) Constitutive model of steel plate.

4.3. Constitutive Relation of Materials. The finite element software ABAQUS provides a CDP (Concrete Damaged Plasticity) model to simulate the material nonlinearity of UHPC. Therefore, it is necessary to find a suitable constitutive model to realize the definition of UHPC materials. The constitutive model adopted is derived from the tensile constitutive proposed by Zhang et al. [43], and the compression constitutive suggested by Yang [44], as shown in Figures 13(a) and 13(b). It should be noted that, in the constitutive compression model, $E_{c}$ is the initial elastic modulus and $E_{s}$ is the elastic modulus of the secant line at the peak point.

The property of the steel plate is defined by the elasticplastic constitutions of linear reinforcement [45] (Figure 13(c)). The constitutive behavior is that the stressstrain relationship increases linearly before the yield stress.
After the yield stress is reached, the strength still increases to a certain extent until the ultimate stress is reached. In the constitutive model of steel plate, $f_{s}$ is $225 \mathrm{MPa}, f_{s u}$ is $370 \mathrm{MPa}, \varepsilon_{s}$ is 0.001 , and $\varepsilon_{s u}$ is 0.101 .

4.4. Numerical Model Validation. In this paper, the epoxy layer's interface element is established based on the cohesive model method, and the load-deflection curve predicted by the finite element model is compared with the test results, as shown in Figure 14. The specific parameters are compared in Tables 7 and 8 .

Combined with the figures and tables, it can be seen that the model is in good agreement with the experimental data, and the variation of the load-deflection curves of the two is consistent. The difference of load and 


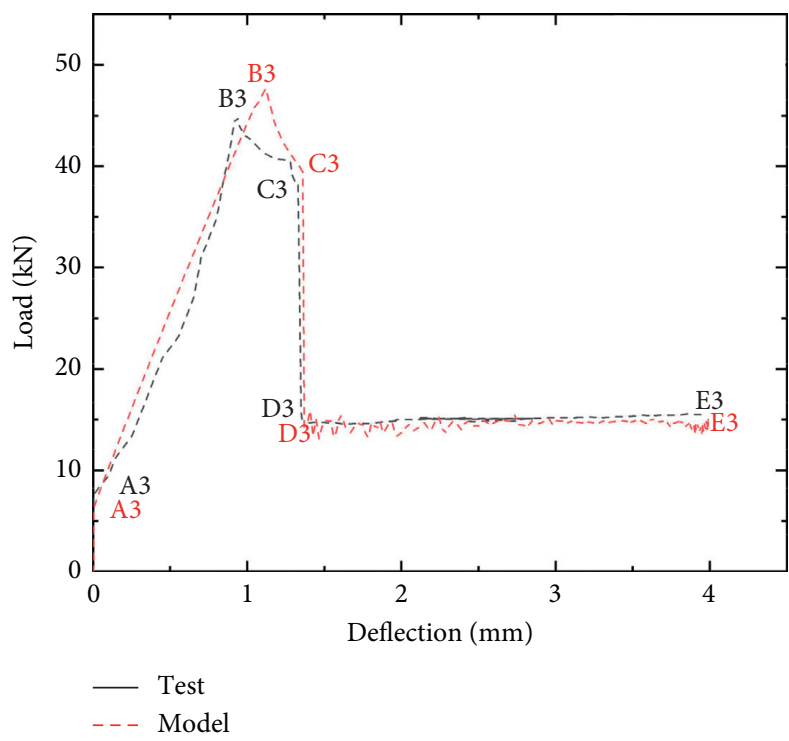

(a)

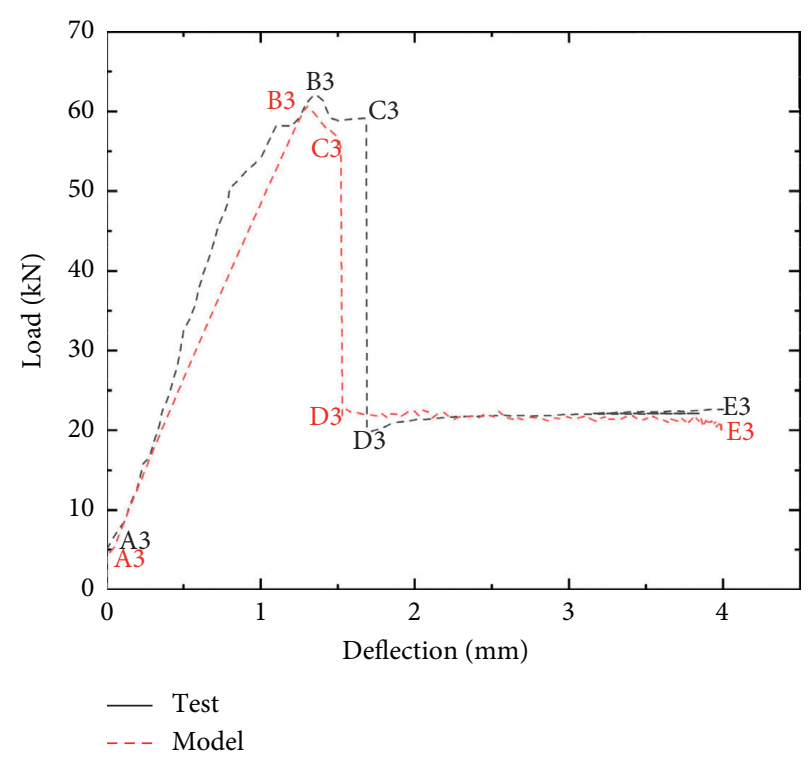

(b)

Figure 14: Comparison of model and test results. (a) CD-ERA-P- $\lambda_{4.44}$ (b) CD-ERA-P- $\lambda_{3.33}$.

TABLE 7: Load-deflection curve and load-slip curve information of specimen CD-ERA-P- $\lambda_{4.44}$.

\begin{tabular}{lcccccc}
\hline Node & $\begin{array}{c}\text { Load } \\
(\mathrm{kN})\end{array}$ & \multicolumn{5}{c}{ Interfacial slip (mm) } \\
& Test & Model & $\begin{array}{c}\text { Difference } \\
(\%)\end{array}$ & Test & Model & $\begin{array}{c}\text { Difference } \\
(\%)\end{array}$ \\
\hline$A_{3}$ & 7.55 & 6.51 & & 0 & 0 & 0 \\
$B_{3}$ & 43.73 & 45.98 & 5.15 & 0.96 & 1.06 & 10.42 \\
$C_{3}$ & 38.46 & 39.61 & 2.99 & 1.33 & 1.36 & 2.26 \\
$D_{3}$ & 15.10 & 14.25 & -5.63 & 1.36 & 1.37 & 0.74 \\
$E_{3}$ & 15.48 & 14.52 & -6.20 & 3.95 & 3.99 & 1.01 \\
\hline
\end{tabular}

TABLE 8: Load-deflection curve and load-slip curve information of specimen CD-ERA-P- $\lambda_{3.33}$.

\begin{tabular}{lcccccc}
\hline \multirow{2}{*}{ Node } & Load $(\mathrm{kN})$ & \multicolumn{5}{c}{ Interfacial slip (mm) } \\
& Test & Model & Test & Test & Model & Difference (\%) \\
\hline$A_{3}$ & 5.01 & 4.47 & -10.78 & 0 & 0 & 0 \\
$B_{3}$ & 62.20 & 60.68 & -2.44 & 1.35 & 1.30 & -3.70 \\
$C_{3}$ & 58.88 & 55.74 & -5.33 & 1.69 & 1.52 & -10.06 \\
$D_{3}$ & 19.92 & 21.85 & 9.69 & 1.71 & 1.53 & -10.53 \\
$E_{3}$ & 22.61 & 20.64 & -8.71 & 4.00 & 3.99 & -0.25 \\
\hline
\end{tabular}

interface slip of each joint is within $15 \%$ and $11 \%$, respectively, indicating that the interface element established by the cohesive method in the model can predict the flexural behavior of epoxy adhesive prefabricated UHPC-steel composite bridge deck.

\section{Conclusion}

In order to study the bending performance of epoxy adhesive prefabricated UHPC-steel composite bridge deck, in this paper, the positive bending moment loading tests with the ratio of shear span to depth of 4.44 and 3.33 were carried out on the specimens of prefabricated UHPC plates and steel plates with different surface treatments. The failure mode, load-deflection curve, interfacial slip, and strain distribution of the specimens are analyzed. Finally, based on the test results, it is verified that the cohesive interface element can effectively simulate the bending performance of epoxy adhesive prefabricated UHPC-steel composite bridge deck. The main conclusions are summarized as follows:

(1) When the ultimate bearing capacity is reached, the bearing capacity of each specimen will not be lost rapidly. After that, there will be a certain increase in interface slip and deflection. It is worth mentioning that the specimen's ultimate failure behavior is that the interface failure is prior to the yield at the bottom of the steel plate, which is characterized by bending failure.

(2) The load-deflection curve can be divided into five stages: elastic stage, crack initiation stage, interfacial crack propagation stage, interface failure stage, and yield stage. The ultimate load $\left(P_{B_{3}}=44.73 \mathrm{kN}\right)$ and increased deflection $\left(\Delta \delta_{B_{i} C_{i}}=0.46 \mathrm{~mm}\right)$ of specimen CD-ERA-P- $\lambda_{4.44}$ are higher than those of other specimens when the ratio of shear span to depth is 4.44. When the ratio of shear span to depth is 3.33 , compared with specimen CD-ERG-P- $\lambda_{3.33}$, the deflection value corresponding to an ultimate load of specimen CD-ERA-P- $\lambda_{3.33}$, and the increased value of deflection at this stage increases to $107.7 \%$ and $75 \%$, respectively. The test results show that when the steel plate's surface is the rough surface (R), and the prefabricated UHPC plate's surface is the aggregate surface (A), the specimen has excellent bearing capacity and bending deformation capacity. 
(3) The results show that the interface slip of the specimen is similar to the deflection, which further indicates that the specimen has higher bearing capacity and the best interface slip capacity when the surface of the steel plate is rough (R), and the surface of the prefabricated UHPC plate is grooved $(A)$. From the interface's final failure state, the reduction of each specimen's ratio of shear span to depth will lead to more complex and diverse failure forms of the interface between the precast UHPC deck and the steel plate, and the final failure of the interface is more sudden.

(4) The strain distribution along the height at the midspan section indicates that certain interfacial slip has occurred in specimen CD-ER-P- $\lambda_{4.44}$ and specimen CD-ER-P- $\lambda_{3.33}$ at the initial stage of loading. For specimen CD-ERG-P- $\lambda_{4.44}$ and specimen CD- ERG-P- $\lambda_{3.33}$, the ratio of shear span to depth reduction results in premature cracking near the loading point when the prefabricated UHPC plate is loaded to the ultimate load. Unlike other specimens, the prefabricated UHPC plate of specimen CD-ERA-P- $\lambda_{4.44}$ cracked near the loading point when loaded to the ultimate load. Moreover, with the decrease of the ratio of shear span to depth, the prefabricated UHPC plate's cracking degree is further aggravated.

(5) The load-deflection curve of the model and the test behave in the same manner. The difference of load and interface slip of each joint is within $15 \%$ and $11 \%$, respectively, which indicates that the cohesive interface element can successfully simulate the prefabricated UHPC-steel epoxy bonding interface and then predict the bending performance of epoxy adhesive prefabricated UHPC-steel composite bridge deck.

\section{Data Availability}

The data needed for verification is already in the literature, and the authors can provide any data needed if necessary.

\section{Conflicts of Interest}

The authors declare that they have no conflicts of interest.

\section{Acknowledgments}

The authors thank for the financial support provided by the National Natural Science Foundation of China (Grant Nos. 52008066 and 51908093), the Natural Science Foundation of Chongqing, China (Grant Nos. cstc2019jcyj-bshX0067 and cstc2019jscx-gksbX0068), the Open Project Program of Key Laboratory of Highway Engineering Materials Technology in High-cold and High-altitude Areas, Communications Surveying, Design and Research Institute of T.A.R. (Grant No. HEMTLAB2019B03), and Science and Technology Projects in T.A.R. (Grant No. XZ202001ZY0054G).

\section{References}

[1] Y. Wang, Z. Wang, Y. Zheng et al., "Analysis of fatigue crack propagation of an orthotropic bridge deck based on the extended finite element method," Advances in Civil Engineering, vol. 2019, Article ID 6319821, 14 pages, 2019.

[2] F. Han, H. Wang, and D. Dan, "A study on dynamic amplification factor and structure parameter of bridge deck pavement based on bridge deck pavement roughness," Advances in Civil Engineering, vol. 2018, Article ID 9810461, 8 pages, 2018.

[3] Z. X. Li, T. H. T. Chan, and J. M. Ko, "Fatigue damage model for bridge under traffic loading: application made to Tsing $\mathrm{Ma}$ Bridge," Theoretical and Applied Fracture Mechanics, vol. 35, no. 1, pp. 81-91, 2001.

[4] Jong De, "Overview fatigue phenomenon in orthotropic bridge decks in the netherlands," in Proceedings of 2004 Orthotropic Bridge Conference, p. 489, ASCE, Sacramento, CA, USA, August 2004.

[5] R. C. Battista, M. S. Pfeil, and E. M. L. Carvalho, "Fatigue life estimates for a slender orthotropic steel deck," Journal of Constructional Steel Research, vol. 64, no. 1, pp. 134-143, 2008.

[6] R. Walter, J. F. Olesen, H. Stang, and T. Vejrum, "Analysis of an orthotropic deck stiffened with a cement-based overlay," Journal of Bridge Engineering, vol. 12, no. 3, pp. 350-363, 2007.

[7] J. Murakoshi, N. Yanadori, and H. Ishii, "Research on steel fiber reinforced concrete pavement on orthotropic steel deck," in Proceedings of the 2nd International Orthotropic Bridge Conference, Sacramento, CA, USA, May 2008.

[8] X. Shao, D. Yi, Z. Huang, H. Zhao, B. Chen, and M. Liu, "Basic performance of the composite deck system composed of orthotropic steel deck and ultrathin RPC layer," Journal of Bridge Engineering, vol. 18, no. 5, pp. 417-428, 2013.

[9] Y. Liu, Q. Zhang, Y. Bao, and Y. Bu, "Fatigue behavior of orthotropic composite deck integrating steel and engineered cementitious composite," Engineering Structures, vol. 220, Article ID 111017, 2020.

[10] Z. Zhang, F. Yang, J.-C. Liu, and S. Wang, "Eco-friendly high strength, high ductility engineered cementitious composites (ECC) with substitution of fly ash by rice husk ash," Cement and Concrete Research, vol. 137, Article ID 106200, 2020.

[11] L. Dieng, P. Marchand, F. Gomes, C. Tessier, and F. Toutlemonde, "Use of UHPFRC overlay to reduce stresses in orthotropic steel decks," Journal of Constructional Steel Research, vol. 89, pp. 30-41, 2013.

[12] Z. Zhang, J.-C. Liu, X. Xu, and L. Yuan, "Effect of sub-elevated temperature on mechanical properties of ECC with different fly ash contents," Construction and Building Materials, vol. 262, Article ID 120096, 2020.

[13] Z. Zhang, F. Qin, H. Ma, and L. Xu, "Tailoring an impact resistant engineered cementitious composite (ECC) by incorporation of crumb rubber," Construction and Building Materials, vol. 262, Article ID 120116, 2020.

[14] Z. Zhang, Q. Zhang, V. C. Li, and Li, "Multiple-scale investigations on self-healing induced mechanical property recovery of ECC," Cement and Concrete Composites, vol. 103, pp. 293-302, 2019.

[15] H. Ma and Z. Zhang, "Paving an engineered cementitious composite (ECC) overlay on concrete airfield pavement for reflective cracking resistance," Construction and Building Materials, vol. 252, Article ID 119048, 2020.

[16] F. Qin, Z. Zhang, Z. Yin, J. Di, L. Xu, and X. Xu, "Use of high strength, high ductility engineered cementitious composites (ECC) to enhance the flexural performance of reinforced 
concrete beams," Journal of Building Engineering, vol. 32, Article ID 101746, 2020.

[17] J. Liu and R. Guo, "Applications of steel slag powder and steel slag aggregate in ultra-high performance concrete," Advances in Civil Engineering, vol. 2018, Article ID 1426037, 8 pages, 2018.

[18] L. Ahmed Sbia, A. Peyvandi, P. Soroushian, J. Lu, and A. M. Balachandra, "Enhancement of ultrahigh performance concrete material properties with Carbon nanofiber," Advances in Civil Engineering, vol. 2014, Article ID 854729, 10 pages, 2014.

[19] S. Xiang and Y. Gao, "Synthesis of pectiniform polyurethanemodified polycarboxylate and its preliminary application in ultrahigh-performance concrete," Advances in Civil Engineering, vol. 2020, Article ID 8859093, 16 pages, 2020.

[20] S. Yuan, Z. Liu, T. Tong, and C. C. Fu, "A pilot study on structural responses of normal concrete-UHPC composite bridge decks w/wo rebars through an experimental-numerical approach," Advances in Civil Engineering, vol. 2020, Article ID 8816337, 21 pages, 2020.

[21] J. Qi, C. Zhao, J. Wang et al., "Full-scale testing on the flexural behavior of an innovative dovetail UHPC joint of composite bridges," Structural Engineering and Mechanics, vol. 75, no. 1, pp. 49-57, 2020.

[22] Y. Wang, X. Shao, J. Chen, J. Cao, and S. Deng, "UHPC-based strengthening technique for orthotropic steel decks with significant fatigue cracking issues," Journal of Constructional Steel Research, vol. 176, Article ID 106393, 2021.

[23] J. Qi, J. Wang, Z. Zhang, W. Li, and Y. Hu, "Flexural behavior of an innovative dovetail ultra-high performance concrete joint using steel wire mesh interface treatment in composite bridges," Advances in Structural Engineering, vol. 23, no. 6, pp. 1142-1153, 2020.

[24] P. Zhang, X. Zou, Q. Li et al., "Experimental study of a novel continuous FRP-UHPC Hybrid Beam," Composite Structures, vol. 261, Article ID 113329, 2020.

[25] M. I. Khan, S. Ahmed, M. K. Rahman et al., "Seismic behavior of beam-column joints strengthened with ultra-high performance fiber reinforced concrete," Composite Structures, vol. 200, pp. 103-119, 2018.

[26] J. Qi, Y. Bao, J. Wang, L. Li, and W. Li, "Flexural behavior of an innovative dovetail UHPC joint in composite bridges under negative bending moment," Engineering Structures, vol. 200, Article ID 109716, 2019.

[27] S. Chen, Y. Huang, P. Gu, and J.-Y. Wang, "Experimental study on fatigue performance of UHPC-orthotropic steel composite deck," Thin-Walled Structures, vol. 142, pp. 1-18, 2019.

[28] C. H. Zhao, W. Kangkang, D. Kailai et al., "Development of fully prefabricated steel-UHPC composite deck system," Journal of Structural Engineering, vol. 145, no. 7, Article ID 04019051, 2019.

[29] X. Shao, W. Qu, J. Cao, and Y. Yao, "Static and fatigue properties of the steel-UHPC lightweight composite bridge deck with large U ribs," Journal of Constructional Steel Research, vol. 148, pp. 491-507, 2018.

[30] X. Zhang, X. Li, R. Liu, C. Hao, and Z. Cao, "Dynamic properties of a steel-UHPC composite deck with large U-ribs: experimental measurement and numerical analysis," Engineering Structures, vol. 213, pp. 491-507, Article ID 110569, 2020.

[31] Y. Zou, "Shear behavior of a novel bearing-shear connector for prefabricated concrete decks," Construction and Building Materials, vol. 268, Article ID 121090, 2020.
[32] Y. Zou, J. Di, J. Zhou et al., "Shear behavior of perfobond connectors in the steel-concrete joints of hybrid bridges," Journal of Constructional Steel Research, vol. 172, Article ID 106217, 2020.

[33] L. Duan, E. Brühwiler, and C.-s. Wang, "Cold stiffening of orthotropic steel decks by a composite UHPFRC layer," Journal of Constructional Steel Research, vol. 172, Article ID 106209, 2020.

[34] L. Bouazaoui, G. Perrenot, Y. Delmas, and A. Li, "Experimental study of bonded steel concrete composite structures," Journal of Constructional Steel Research, vol. 63, no. 9, pp. 1268-1278, 2007.

[35] Y. Zou, "Partial interaction shear flow forces in simply supported composite steel-concrete beams," Advanced Steel Construction, vol. 14, no. 4, pp. 634-650, 2018.

[36] A. Si Larbi, E. Ferrier, and P. Hamelin, "Concrete to steel lap joint failure criteria under combined shear and peeling stress," Journal of Constructional Steel Research, vol. 65, no. 2, pp. 386-394, 2009.

[37] B. Jurkiewiez, C. Meaud, and L. Michel, "Non linear behaviour of steel-concrete epoxy bonded composite beams," Journal of Constructional Steel Research, vol. 67, no. 3, pp. 389-397, 2011.

[38] X. Y. He, "Mechanical properties of orthotropic steel deck with epoxy adhesively bonded rigid pavement," Journal of Harbin Institute of Technology, vol. 52, no. 9, pp. 25-31, 2020.

[39] P. Buitelaar, B. Rene, and K. Neik, "Reinforced high performance concrete overlay system for steel bridges," in Proceedings of the 5th International CROW Workshop On Fundamental Modelling of the Design and Performance of Concrete Pavements, Istanbul, Turkey, April 2004.

[40] Z. Wang, X. Nie, J.-S. Fan, X.-Y. Lu, and R. Ding, "Experimental and numerical investigation of the interfacial properties of non-steam-cured UHPC-steel composite beams," Construction and Building Materials, vol. 195, pp. 323-339, 2019.

[41] Y. Zou, J. Jiang, Z. Zhou, X. Wang, and J. Guo, "Study on the static performance of prefabricated UHPC-steel epoxy bonding interface," Advances in Civil Engineering, vol. 2021, Article ID 6663517, 15 pages, 2021.

[42] Q. Sun, X. Lu, X. Nie, Z. Han, and J. Fan, "Experimental research on tensile and shear behaviour of the interface between non-steam-cured uhpc and steel plate structure," Mechanical Engineering, vol. 34, no. 9, pp. 167-174, 2017.

[43] Z. Zhang, X. Shao, W. Li, P. Zhu, and H. Chen, "Axial tensile behavior test of ultra high performance concrete China," Journal of Traffic and Transportation Engineering, vol. 28, no. 8, pp. 50-58, 2015.

[44] J. Yang, Flexural Behavior of Ultra-high Performance Concrete Beams Prestressed with CFRP Tendons, Hunan University, Changsha, China, 2007.

[45] Ministry of Housing and Urban-Rural Development of the People's Republic of China, Code for Design of Concrete Structures (GB 50010-2010), China Planning Press, Beijing, China, 2015, In Chinese. 